\title{
TAp73/DNp73 influences apoptotic response, chemosensitivity and prognosis in hepatocellular carcinoma
}

\author{
M Müller ${ }^{*, 1,8}$, T Schilling $^{2,8}$, AE Sayan ${ }^{3}$, A Kairat ${ }^{1}, K_{\text {Lorenz }}{ }^{1}$, \\ H Schulze-Bergkamen ${ }^{4}$, M Oren $^{5}$, A Koch $^{1}$, A Tannapfel ${ }^{6}$, \\ W Stremmel ${ }^{1,9}$, G Melino $^{3,7,9}$ and PH Krammer ${ }^{4,9}$ \\ 1 Department of Internal Medicine IV, Hepatology and Gastroenterology, \\ University of Heidelberg, Im Neuenheimer Feld 410, 69120 Heidelberg, \\ Germany \\ 2 Department of Internal Medicine I, Endocrinology and Metabolism, University \\ of Heidelberg, Im Neuenheimer Feld 410, 69120 Heidelberg, Germany \\ ${ }^{3}$ MRC Toxicology Unit, Leicester University, Leicester LE1 9HN, UK \\ 4 Tumor Immunology Program, German Cancer Research Center (DKFZ), Im \\ Neuenheimer Feld 280, 69120 Heidelberg, Germany \\ 5 Department of Molecular Cell Biology, The Weizmann Institute, Rehovot \\ 76100 , Israel \\ ${ }^{6}$ Institute of Pathology, University of Leipzig, Liebigstrasse 26, 04103 Leipzig, \\ Germany \\ ${ }^{7}$ Biochemistry Laboratory, IDI-IRCCS, c/o Department of Experimental \\ Medicine and Biochemical Sciences, University of Rome, 00133 Rome, Italy \\ 8 These authors contributed equally to this work. \\ 9 These authors share last authorship. \\ * Corresponding author: M Müller, Department of Internal Medicine IV, \\ Hepatology and Gastroenterology, University of Heidelberg, Im Neuenheimer \\ Feld 410, 69120 Heidelberg, Germany. Tel: + 49622156 38795; \\ Fax: + 49622156 4395; \\ E-mail: Martina_Mueller-Schilling@med.uni-heidelberg.de
}

Received 20.6.05; revised 25.7.05; accepted 05.8.05; published online 30.9.05 Edited by D Green

\section{Abstract \\ We investigated the mechanisms by which TAp73 $\beta$ and dominant-negative $p 73(\Delta N p 73)$ regulate apoptosis. TAp73 $\beta$ transactivated the CD95 gene via the p53-binding site in the first intron. In addition, TAp73 $\beta$ induced expression of proapoptotic Bcl-2 family members and led to apoptosis via the mitochondrial pathway. Endogenous TAp73 was upregulated in response to DNA damage by chemotherapeutic drugs. On the contrary, $\Delta$ Np73 conferred resistance to chemotherapy. Inhibition of CD95 gene transactivation was one mechanism by which $\Delta \mathrm{Np73}$ functionally inactivated the tumor suppressor action of p53 and TAp73 $\beta$. Concomitantly, $\Delta$ Np73 inhibited apoptosis emanating from mitochondria. Thus, $\triangle N p 73$ expression in tumors selects against both the death receptor and the mitochondrial apoptosis activity of TAp73 $\beta$. The importance of these data is evidenced by our finding that upregulation of $\triangle N p 73$ in hepatocellular carcinoma patients correlates with reduced survival. Our data indicate that $\Delta \mathrm{Np} 73$ is an important gene in hepatocarcinogenesis and a relevant prognostic factor. Cell Death and Differentiation (2005) 12, 1564-1577. doi:10.1038/sj.cdd.4401774; published online 30 September 2005}

Keywords: apoptosis; CD95; chemosensitivity; hepatocellular carcinoma; dominant-negative p73; TAp73

\begin{abstract}
Abbreviations: ANOVA, analysis of variance; $\Delta \mathrm{Np} 73$, dominant-negative p73; FACS, fluorescence-activated cell sorting; FADD, Fas-associated death domain; GFP, green fluorescent protein; HCC, hepatocellular carcinoma; MANOVA, multivariate analysis of variance; MEF, mouse embryo fibroblast; p53-IBS, intronic p53-binding site; SAM, significance analysis of microarrays
\end{abstract}

\section{Introduction}

The discovery of a $\Delta \mathrm{Np} 73$ (dominant-negative p73)-based p53-p73 interference network suggests that the p53 status of a tumor should no longer be regarded as the sole predictor of clinical outcome and therapeutic responsiveness.

TP53 is the prototype tumor suppressor gene in human cancer due to its proapoptotic and antiproliferative function in response to oncogenic stress. The 053 pathway is inactivated in the majority of human malignancies. ${ }^{1}$ TP73, despite significant homology to p53, is not a classic Knudson-type tumor suppressor gene. ${ }^{2-4}$ TP73-deficient mice lack a tumor phenotype ${ }^{5}$ and inactivating mutations in patients suffering from cancer are extremely rare. ${ }^{3}$

The expression of the TP73 gene is complicated by the presence of several splicing isoforms at the C-terminus $(p 73 \alpha-\zeta)^{2,3,6,7}$ and of two distinct promoters, driving the expression of $p 53$-like proteins containing the transactivation domain (TAp73), and inhibitory proteins lacking TA, called $\Delta$ TAp73 (the collective name for four different p73 TAdeficient forms, mainly $\Delta \mathrm{Np} 73) . \Delta \mathrm{Np} 73$ acts as a potent transdominant inhibitor of TAp73 and wild-type p53. ${ }^{3,8}$ Thus, the TP73 locus encodes both a tumor suppressor (TAp73) and a putative oncogene $(\Delta \mathrm{Np} 73)$.

The finding that a significant percentage of tumors specifically select for dominant-negative p73 isoforms strongly argues for their oncogenic role during tumorigenesis. ${ }^{8,9} \Delta \mathrm{Np} 73$ cooperates with oncogenic Ras in transforming primary mouse embryo fibroblasts (MEFs) in vitro and in inducing MEF-derived fibrosarcomas in nude mice in vivo. ${ }^{10}$ Furthermore, mice heterozygous for mutations in both p53 and p63 or p63 and p73 displayed higher tumor burden and metastasis compared to p53 $+/-$ mice $^{11}$

Endogenous TAp73 is activated in response to a variety of chemotherapeutic drugs and gamma-irradiation in a pathway that depends on the non-receptor tyrosine kinase c-Abl. ${ }^{12,13}$ We have recently described a role for TAp63 $\alpha$ in the induction of apoptosis and chemosensitivity. ${ }^{14}$

The involvement of p63 and p73 in p53-mediated apoptosis is controversial. Whereas on the one hand the presence of p63 and p73 has been shown to be essential for p53 to induce apoptosis in fibroblasts following DNA damage ${ }^{15}$ results of a recent study indicate on the other hand, that at least in thymocytes, p53-dependent apoptosis occurs independently of $p 63$ and $p 73 .^{16}$ 
Given the possible role of TAp73 and $\Delta \mathrm{Np} 73$ isoforms in cancer, it is of great interest to determine how they regulate apoptosis, as the critical process which links tumor development, treatment sensitivity and clinical outcome.

We have analyzed the mechanisms of TAp73/ANp73regulated apoptosis and their relevance for chemosensitivity and prognosis in hepatocellular carcinoma (HCC).

Our data suggest possible signaling pathways through which the balance between TAp73 and $\triangle N p 73$ regulates the apoptosis response of cancer cells, thereby playing a decisive role in the choice between elimination of cancer-prone cells versus hepatocarcinogenesis as well as between treatment sensitivity versus drug resistance. Of clinical importance, we show that $\Delta \mathrm{Np} 73$ is a predictor of adverse outcome and a new prognostic factor in $\mathrm{HCC}$.

\section{Results}

\section{TAp73 $\beta$-induced apoptosis involves activation of caspases}

Adenoviral transfer of the TAp73 $\beta$ gene into Hep3B cells induced apoptosis in a dose-dependent manner (Figure 1a). TAp73 $\beta$-mediated apoptosis was strongly inhibited by the caspase inhibitors ZVAD-FMK, DEVD-FMK, Z-IETD-FMK and Z-LEHD-FMK (Figure 1b and c). Involvement of caspases was confirmed by fluorometric determination of the increased enzymatic activity of the caspase-3, -8 and -9 class of proteases (Figure 1d).

\section{Microarray analysis of TAp73 $\beta$-mediated apoptosis}

Since TAp73 $\beta$ was able to induce classical apoptosis (Figure 1) and since TAp73 is a transcription factor, we decided to investigate the underlying molecular mechanisms by performing a gene array analysis. Following adenoviral TAp73 $\beta$ transfer the genes encoding for the death receptors CD95, TNF-R1, TRAIL-R1 and -R2 were found to be upregulated (Table 1). Additional evidence for the involvement of receptor-mediated signaling in TAp73 $\beta$-induced apoptosis was provided by the fact that the pro-caspase-8binding adapter protein Fas-associated death domain (FADD) was found to be upregulated.

Activation of caspases is clearly involved in mediating TAp73 $\beta$-induced downstream apoptosis signaling. Caspase$1,-2,-3,-4,-6,-8,-9$ and -10 were found to be upregulated in response to $\operatorname{TAp} 73 \beta$ (Table 1 ).

Furthermore, we identified the genes encoding the proapoptotic Bcl-2 family members BAD and BIK and the genes encoding BNIP3, HRK and RAD9 as targets for transcriptional upregulation in cells overexpressing TAp73 $\beta$ (Table 1). Thus, microarray analyses provide evidence that TAp73 $\beta$ stimulates both, genes that regulate the extrinsic apoptosis pathway initiated by ligation of death receptors and genes that regulate the intrinsic/mitochondrial apoptosis pathway.

\section{TAp73 $\beta$ triggers the extrinsic apoptosis pathway via activation of death receptors}

We have previously shown that the CD95 gene is a transcriptional target of wt p53, whose expression is induced

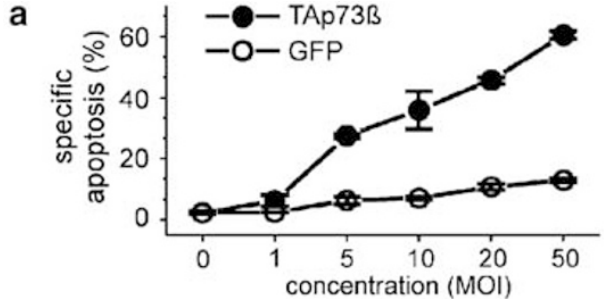

b
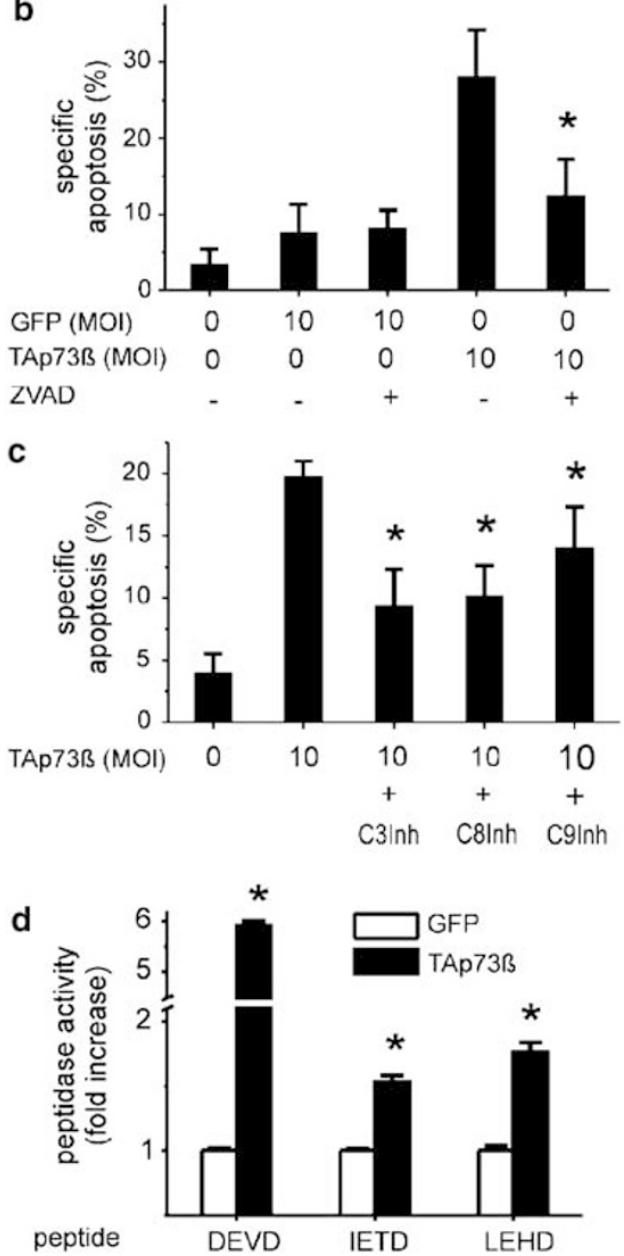

Figure 1 Apoptosis induced by TAp73 $\beta$ involves caspase activation. (a) TAp73 $\beta$ induces dose-dependent apoptosis of hepatoma cells (Hep3B) within $72 \mathrm{~h}$. Data obtained in two separate experiments were averaged, values are mean \pm S.D., $n=6$. (b) TAp73 $\beta$-dependent apoptosis was blocked by the broad-spectrum caspase inhibitor zVAD $(50 \mu \mathrm{M})$, indicating that TAp73 $\beta$ dependent cell death involves caspase-activation. A FACScan ${ }^{\circledR}$ analysis of propidium iodide-stained nuclei ${ }^{20}$ of Hep3B cells $(72 \mathrm{~h})$ is shown. Data obtained in five separate experiments were averaged, values are mean \pm S.D., $n=15$. ${ }^{\star} P<0.0001$ compared to TAp73 $\beta, 10 \mathrm{MOI}$, Wilcoxon test. (c) The caspase inhibitors DEVD-FMK (C3Inh), Z-IETD-FMK (C8Inh) and Z-LEHD-FMK (C9Inh) significantly reduced TAp73 $\beta$-dependent apoptosis. Three independent experiments were performed, and a representative result is shown. Mean+S.D., $n=3$. ${ }^{*} P<0.05$ compared to TAp73 $\beta, 10 \mathrm{MOI}$, Wilcoxon test. (d) Determination of the increased enzymatic activity of the caspase-3, -8 and -9 class of proteases was performed by fluorometric assays $48 \mathrm{~h}$ following rAd-TAp73 $\beta$ transfer (10 MOI) into Hep3B cells. Fold activation represents the DEVDase- (consistent with caspase 3-), IETDase- (consistent with caspase 8-) and LEHDase(consistent with caspase 9-) activity of Hep3B cells transduced by rAd-TAp73 $\beta$ compared to cells transduced by rAd-GFP. Three independent experiments were performed, and a representative result is shown. Mean \pm S.D., $n=3$. ${ }^{\star} P<0.05$, Wilcoxon test 


\begin{tabular}{|c|c|c|c|c|c|c|c|c|c|c|c|c|c|c|c|c|c|c|}
\hline \multicolumn{5}{|c|}{ Feature } & \multicolumn{6}{|c|}{ Reporter } & \multicolumn{4}{|c|}{ Composite sequence } & \multicolumn{4}{|c|}{ Fold activation $^{\mathrm{b}}$} \\
\hline \multicolumn{5}{|c|}{ Coordinates on arrays } & $\begin{array}{c}\text { Reporter ID } \\
\text { (RZPD defined) }\end{array}$ & $\begin{array}{l}\text { Bio-sequence } \\
\text { type }\end{array}$ & Clone ID & $\begin{array}{c}\text { Genbank } \\
\text { Access. No. }\end{array}$ & $\begin{array}{l}\text { Reporter } \\
\text { usage }\end{array}$ & $\begin{array}{c}\text { Control } \\
\text { type }\end{array}$ & Comp. ID & Designation & $\begin{array}{l}\text { Related gene } \\
\text { symbol }\end{array}$ & Database entry & $12 \mathrm{~h}$ & $24 \mathrm{~h}$ & $36 \mathrm{~h}$ & $48 \mathrm{~h}$ \\
\hline X-Pos & Y-Pos & $\begin{array}{l}\text { Spot } \\
\text { plate }\end{array}$ & Row & Column & & & & & & & & & & & & & & \\
\hline \multicolumn{19}{|c|}{ Death receptor-mediated apoptosis } \\
\hline 34 & 27 & 1 & A & 13 & 1048421 & cDNA clone & IMAGp998E031157 & X65019 & Exp & - & 005-B03 & Caspase 1 & CASP1 & LocusID834 & & & & 2.33 \\
\hline 53 & 15 & 3 & L & 7 & 2924855 & cDNA clone & IMAGp958B2446 & U13022 & $\operatorname{Exp}$ & - & 011-F04 & Caspase 2 & CASP2 & LocusID835 & & & & 2.36 \\
\hline 43 & 12 & 1 & M & 10 & 49729 & cDNA clone & IMAGp998G22281 & U13737 & Exp & - & 002-G05 & Caspase 3 & CASP3 & LocusID836 & 0.67 & 4.05 & & 1.76 \\
\hline 1 & 15 & 1 & L & 24 & 302539 & cDNA clone & IMAGp998C20678 & U28014 & Exp & - & 004-F12 & Caspase 4 & CASP4 & LocusID837 & 3.73 & 0.44 & 0.04 & 1.45 \\
\hline 27 & 26 & 2 & $\mathrm{H}$ & 16 & 323500 & cDNA clone & IMAGp998M05732 & U20536 & Exp & - & $008-\mathrm{D} 08$ & Caspase 6 & CASP6 & LocusID839 & & 3.78 & 0.47 & \\
\hline 47 & 15 & 3 & L & 9 & 338776 & cDNA clone & IMAGp998|17772 & $\begin{array}{l}\text { X98175 } \\
\end{array}$ & $\operatorname{Exp}$ & - & 009-D12 & Caspase 8 & CASP8 & LocusID841 & & 2.96 & 2.17 & 1.47 \\
\hline $\begin{array}{l}41 \\
37\end{array}$ & 12 & 1 & M & 12 & 121693 & cDNA clone & IMAGp998D14114 & U60521 & $\begin{array}{l}\operatorname{Exp} \\
\operatorname{Exp}\end{array}$ & - & 002-G06 & Caspase 9 & CASP9 & LocusID842 & 0.26 & & 2.17 & $\begin{array}{l}1.41 \\
5.74\end{array}$ \\
\hline 60 & 41 & 2 & $\mathrm{c}$ & 5 & 1048421 & cDNA clone & IMAGp998J062620 & AA773725 & $\operatorname{Exp}$ & - & 005-B03 & Caspase 10 & CASP10 & LocusID843 & & 5.57 & 0.53 & 3.32 \\
\hline 18 & $\begin{array}{l}41 \\
26\end{array}$ & 2 & $\mathrm{H}$ & 19 & 309671 & cDNA clone & IMAGp998L24696 & $\times 84709$ & $\operatorname{Exp}$ & - & 007-D10 & $\begin{array}{l}\text { Fas (TNFRSF\&-) } \\
\text { assoc. via death } \\
\text { dom. }\end{array}$ & FADD & LocusID8772 & & 2.26 & 0.61 & \\
\hline 42 & 20 & 2 & $\mathrm{~J}$ & 11 & 1693595 & cDNA clone & IMAGp998L124300 & M10988 & Exp & - & 007-E06 & $\begin{array}{l}\text { Tumor necrosis } \\
\text { factor }\end{array}$ & TNF & LocusID7124 & & & & 2.26 \\
\hline 6 & 38 & 2 & D & 23 & 2521744 & cDNA clone & IMAGp998F176279 & М3з294 & Exp & - & 007-B12 & $\begin{array}{l}\text { Tumor necrosis- } \\
\text { factor recept. } \\
\text { superf.-m. } 1 \mathrm{~A}\end{array}$ & $\begin{array}{l}\text { TNFRSF1A/TNF- } \\
\text { R1 }\end{array}$ & - LocusID7132 & 2.02 & & 1.96 & \\
\hline 18 & 26 & 2 & $\mathrm{H}$ & 19 & 309671 & cDNA clone & IMAGp998L24696 & M67454 & Exp & - & 007-D10 & $\begin{array}{l}\text { Tumor necrosis } \\
\text { factor recept. } \\
\text { superf-m. } 6\end{array}$ & TNFRSF6/CD95 & LocusID355 & & 2.27 & 2.44 & \\
\hline 60 & 26 & 2 & H & 5 & 526788 & cDNA clone & IMAGp998C131262 & U90875 & Exp & - & 007-D03 & $\begin{array}{l}\text { Tumor necrosis } \\
\text { factor recept. } \\
\text { superf.-m. } 10 \mathrm{~A}\end{array}$ & $\begin{array}{l}\text { TNFRSF10A/ } \\
\text { TRAIL-R1 }\end{array}$ & LocusID8797 & & & & 2.56 \\
\hline 72 & 14 & 2 & L & 1 & 3948060 & cDNA clone & IMAGp958L13810 & AF016268 & Exp & - & 007-F01 & $\begin{array}{l}\text { Tumor necrosis } \\
\text { factor recept. } \\
\text { superf.-m. 10B }\end{array}$ & $\begin{array}{l}\text { TNFRSF10B/ } \\
\text { TRAIL-R2 }\end{array}$ & LocusID8795 & & & 0.36 & 1.55 \\
\hline \multicolumn{19}{|c|}{ Mitochondrial genes } \\
\hline 46 & 48 & 1 & A & 9 & 239688 & cDNA clone & IMAGp998101514 & U66879 & Exp & - & 001-A05 & $\begin{array}{l}\text { BCL2-antagonist } \\
\text { of cell death }\end{array}$ & BAD & LocusID572 & 1.97 & & & 2.44 \\
\hline 41 & 39 & 3 & D & 11 & 2814845 & cDNA clone & IMAGp998K066967 & X89986 & Exp & - & 011-B06 & $\begin{array}{l}\text { BCL2-interacting } \\
\text { killer (apoptosis } \\
\text { inducing) }\end{array}$ & BIK & LocusID638 & & 2.11 & & 3.64 \\
\hline 18 & 47 & 2 & A & 19 & 51927 & cDNA clone & IMAGp998B117286 & AF002697 & $\operatorname{Exp}$ & - & 005-A10 & $\begin{array}{l}\text { BCL2-adenovirus } \\
\text { E1B 19kDa- } \\
\text { interact. prot. } 3\end{array}$ & BNIP3 & LocusID664 & & & & 5.03 \\
\hline 57 & 44 & 2 & B & 6 & 767779 & cDNA clone & IMAGp998L201889 & U76376 & Exp & - & 008-A03 & $\begin{array}{l}\text { harakiri, BCL2- } \\
\text { interacting protein }\end{array}$ & HRK & LocusID8739 & & 2.07 & & 2.16 \\
\hline 35 & 3 & 3 & $\mathrm{p}$ & 13 & 713617 & cDNA clone & IMAGp998L021748 & U53174 & Exp & - & 011-H07 & $\begin{array}{l}\text { RAD9 (S. pombe) } \\
\text { homolog, (nucl. } \\
\text { and mitochondr. } \\
\text { local. apoptosis } \\
\text { inducer) }\end{array}$ & RAD9 & LocusID5883 & 1.93 & & & \\
\hline 32 & 9 & 3 & $\mathrm{~N}$ & 14 & 148920 & cDNA clone & IMAGpC01228 & $\begin{array}{c}\text { Cont } \\
\mathrm{H} 13168\end{array}$ & $\begin{array}{l}\text { trol clones } \\
\text { Control }\end{array}$ & Pos & - & $\begin{array}{l}\text { Hemoglobin, } \\
\text { alpha } 1\end{array}$ & HBA1 & LocusID3039 & nan & nan & nan & nan \\
\hline 20 & 33 & 3 & $\mathrm{~F}$ & 18 & 203166 & cDNA clone & IMAGpG07392 & R44290 & Control & Pos & - & Actin, beta & actin1 & LocusID51164 & nan & nan & nan & nan \\
\hline 44 & 9 & 3 & $\mathrm{~N}$ & 10 & 201154 & cDNA clone & IMAGpC11387 & R17745 & Control & Pos & - & Transferrin & TF & LocusID7018 & nan & nan & nan & nan \\
\hline
\end{tabular}

${ }^{\mathrm{a}}$ These data have been submitted to EMBL Nucleotide Sequence Database. ${ }^{\mathrm{b}}$ Fold activation of TAp73ß-dependent genes relative to GFP $(=1)$ as evaluated by SAM (six independent hybridizations) is shown. nan $=$ not a number 
through binding of wt p53 to a regulatory region residing within its first intron. ${ }^{17,18}$. Based on these observations, we next investigated if $\operatorname{TAp} 73 \beta$, like $\mathrm{p} 53$, induces CD95-dependent apoptosis by upregulating the expression of the CD95 receptor itself. Semiquantitative RT-PCR showed an increase in the amount of CD95 mRNA in Hep3B cells following adenoviral TAp73 $\beta$ transfer (Figure 2a).

Importantly, FACS analysis revealed that overexpression of TAp73 $\beta$ led to an increase in the amount of CD95 displayed on the cell surface in Hep3B (Figure $2 b$ and $c$ ). This increase in CD95 expression was also observed in a second cellular model, in Saos2 cells (Figure 2d). Saos2 cells are p53 negative and show no detectable levels of p63 and p73 at either mRNA or protein level. a

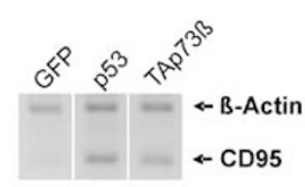

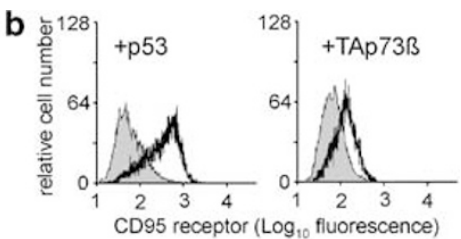
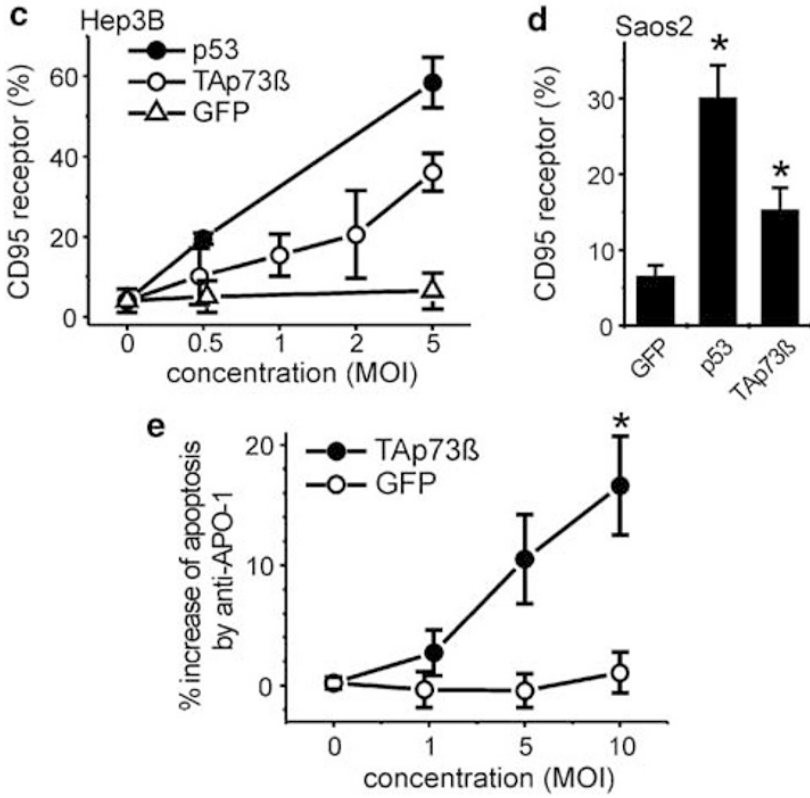

Figure $2 \mathrm{TAp} 73 \beta$ induces upregulation of the $\mathrm{CD} 95$ receptor and sensitizes towards CD95-mediated apoptosis. (a) TAp73 $\beta$, like $\mathrm{p} 53$, induces upregulation of CD95 mRNA. Semiquantitative PCR-analysis of CD95 mRNA expression following adenoviral transfer $(24 \mathrm{~h})$ of either rAd-GFP, rAd-p53 or rAd-TAp73 $\beta$ (10 MOI each) into Hep3B cells (p53-/-). (b) FACScan ${ }^{R}$ analysis of CD95 receptor expression in Hep3B cells following transduction by either rAd-GFP, rAd-p53 or rAd-TAp73 $\beta$ (5 MOI each). Transfer of rAd-TAp73 $\beta$ (72 h) as well as restitution of a wt p53 status restores the ability of the p53-/ - cell line Hep3B to increase the CD95 receptor. Presented are representative diagrams of $\mathrm{FL}-2$ (CD95) for rAd-p53 and rAd-TAp73 $\beta$. (c + d), TAp73 $\beta$ induces upregulation of the CD95 receptor in Hep3B (dose dependent) and in Saos2 cells (50 MOI). FACScan ${ }^{\mathbb{R}}$ analyses were performed in triplicates, six independent experiments were performed, a representative result is shown (mean \pm S.D., $n=3$ ) ${ }^{\star} P<0.05$ compared to GFP, Wilcoxon test. (e) TAp73 $\beta$ sensitizes Hep3B cells towards CD95-mediated apoptosis. Only Hep3B cells transduced by rAdTAp73 $\beta$ exhibited a significantly increased responsiveness towards induction of apoptosis by anti-APO-1. Data are expressed as \% increase in specific apoptosis due to addition of anti-APO-1. FACScan ${ }^{\circledR}$ analysis following Nicoletti staining. A representative result of three independent experiments is shown, presented is mean \pm S.D., $n=4 .{ }^{*} P<0.0001$, MANOVA, between-subject effect
The increased number of death receptors on the cell surface is likely to increase sensitivity of cancer cells towards apoptosis. We tested this hypothesis by treating Hep3B cells with agonistic anti-APO-1 antibody. Figure $2 \mathrm{e}$ shows that the antibody is in fact able to trigger cell death in TAp73 $\beta$ overexpressing Hep3B cells, but not in cells infected with a control green fluorescent protein (GFP)-adenovirus. This indicates that TAp73 $\beta$ induces the expression of a functional CD95 death receptor on the cell surface.

\section{TAp73 is a transcriptional activator of the CD95 gene}

Upregulation of CD95 mRNA and protein by TAp73 $\beta$ might be due to direct transcriptional activation of the CD95 gene. Since most of the TAp73 $\beta$-driven promoters seem to share p53-responsive elements, we investigated the possibility that TAp73 $\beta$ transactivates the CD95 gene via binding to the intronic p53-binding site ${ }^{17,18}$ (Figure 3a). This was carried out by transient transfection assays, employing plasmid p1142CD95-luc.

Figure $3 c$ shows that cotransfection of the TAp73 isoforms $\alpha, \beta, \gamma$ and $\delta$ significantly increased p1142CD95-luc activity. This supports the hypothesis that TAp73 can induce CD95 gene expression. The TAp73-dependent transactivation of the CD95 gene strictly depends on the intronic p53-binding site, as it is totally abrogated when using a CD95 luciferase construct (Figure $3 \mathrm{c}$ ) with a mutated intronic p53-binding site (Figure $3 b$ ). This argues strongly in favor of the conclusion that the CD95 gene is a direct transcriptional target of TAp73.

\section{$\Delta N p 73$ is an efficient inhibitor of the transcriptional activity of TAp73 and inhibits both transactivation of the CD95 gene and apoptosis}

As shown in Figure $4 a, \Delta N p 73$ is a strong inhibitor of TAp73mediated CD95 gene transactivation. $\triangle \mathrm{Np73}$ is not able to transactivate the CD95 gene by itself. In addition, Figure $4 \mathrm{~b}$ shows the capacity of the $\Delta 84 p 73 \beta$ isoform, which is functionally equivalent to the $\Delta 2 p 73, \Delta 3 p 73$ and $\Delta 23 p 73$ isoforms, ${ }^{2}$ to abrogate TAp73-mediated transactivation of the CD95 gene. Furthermore, $\Delta 84 \mathrm{p} 73 \beta$ blocks p53-mediated transactivation of the CD95 promoter (Figure 4c). Thus, interference with the CD95 gene transactivation-capacity of TAp73 and that of p53 constitutes a molecular mechanism by which $\mathrm{N}$ terminus-deleted p73-isoforms exert their antiapoptotic action. This implies that the presence of the $\Delta \mathrm{Np} 73$ (or $\Delta 84 p 73 \beta$ ) protein constitutes a dominant-negative effect controlling apoptosis in hepatoma cells. To test this hypothesis, we evaluated the regulation of apoptosis by $\Delta N p 73$. Hep3B cells undergo TAp73 $\beta$-dependent cell death as assessed by FACS analysis. This apoptotic activity is completely abolished by the coexpression of $\Delta 84 \mathrm{p} 73 \beta$ (Figure 4d).

\section{TAp73 $\beta$ engages mitochondrial apoptosis pathways}

In order to further characterize the molecular mechanisms of TAp73-mediated apoptosis, we investigated the influence of 
a
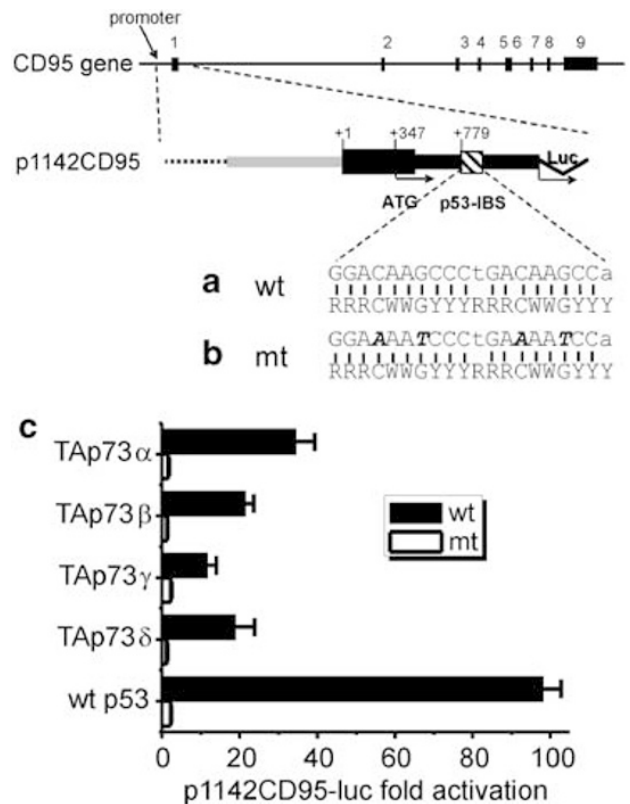

Figure 3 TAp73 transactivates the CD95 gene via the intronic p53-binding site. Map of the human CD95 gene. Exons 1-9 are numbered according to Wada et $a l^{38}$ and represented by black boxes. The striped box indicates the intronic p53-binding site (p53-IBS) in the first intron of the CD95 gene. ${ }^{18}$ (a) Wild-type (wt) sequence of the CD95 intronic p53-binding site. ${ }^{18}$ This sequence (top line) is compared with the consensus p53-binding site (bottom line) according to El-Deiry et al. ${ }^{39}$ Missing vertical bars indicate deviations in the wt sequence from the consensus. $\mathrm{R}=$ purine, $\mathrm{Y}=$ pyrimidine, $\mathrm{W}=\mathrm{A}$ or $\mathrm{T}$. (b) In plasmid $\mathrm{mt}$ p1142CD95-luc, essential nucleotides for the binding of wt p53 protein have been mutated in the intronic p53-responsive element. (c) The TAp73 isoforms $\alpha$, $\beta, \gamma$ and $\Delta$ transactivated the CD95 gene via binding to the p53-binding site in its first intron. Mutation of this binding site (mt p1142CD95-luc) completely abrogated binding and transactivation by TAp73-isoforms. Cells were transfected with $1 \mu \mathrm{g}$ of plasmid p1142CD95-luc together with $100 \mathrm{ng}$ of either a wt p53plasmid, or a TAp73 $\alpha, \beta, \gamma$ or $\Delta$-plasmid, or an equivalent amount of empty vector. Presented is the fold p53- or TAp73-dependent activation of the p1142CD95-luc reporter plasmid, calculated relative to the value obtained with the same reporter in the absence of $p 53$ or the TAp73-isoforms. Assays were performed in triplicates in five independent experiments. One representative experiment is shown (mean \pm S.D., $n=3$ )

TAp73 $\beta$ on mitochondrial apoptosis signaling. FACS analysis following JC-1 staining revealed an alteration of the mitochondrial membrane potential following adenoviral TAp73 $\beta$ transfer in Hep3B cells (Figure 5a).

To investigate the possible involvement of Bax in p73induced apoptosis, we performed a transient transfection assay using a reporter plasmid (Bax-Pr/luc) containing the full-length Bax promoter placed upstream of a luciferase cDNA (Figure $5 b$ ). Figure $5 c$ shows that cotransfection of TAp73 $\beta$ significantly increased Bax-Pr/luc activity. Western blot analysis confirmed induction of endogenous Bax protein following rAd-TAp73 $\beta$ transfer (Figure $5 d$ ). In addition, as shown by microarray analysis, BAD, BIK, BNIP3, HRK and RAD9 were induced (Table 1). Thus, TAp73 $\beta$ contributes to apoptosis by inducing the expression of several proapoptotic genes involved in mitochondrial signaling.

Blocking TAp73 $\beta$ by rAd- $\Delta 84 p 73 \beta$ significantly decreased Bax-Pr/luc activity. Furthermore, $\Delta 84 p 73 \beta$ did also block $p 53-$ mediated transactivation of the Bax promoter (Figure $5 \mathrm{e}$ ). Thus, in addition to interference with the death receptor-

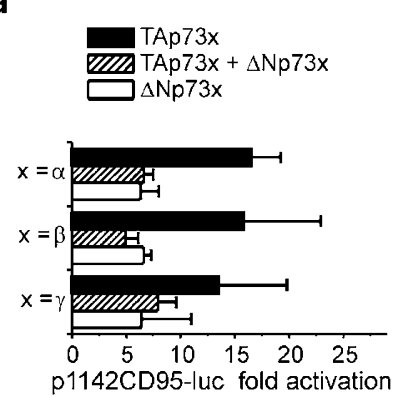

C

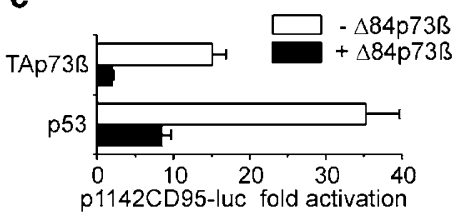

$\triangle 84 \mathrm{p} 73 ß(\mathrm{MOI}) \quad 0 \quad 0 \quad 1010$

Figure 4 Dominant-negative $(\Delta N) p 73 \beta$ and delta $(\Delta) 84 p 73 \beta$ inhibit TAp73and p53-mediated transactivation of the CD95 gene and counteract apoptosis induced by TAp73 $\beta$. (a-c), analysis of TAp73-dependent luciferase activity. Hep3B cells were transfected with $1 \mu \mathrm{g}$ of plasmid p1142CD95-luc together with $100 \mathrm{ng}$ of either a TAp73 $\alpha, \beta, \gamma$ or $\Delta$-plasmid, a p53-plasmid, or an equivalent amount of empty vector alone or together with the respective $\Delta$ Np73- or $\Delta 84$ isoform. Presented is the fold TAp73- or p53-dependent activation of each reporter plasmid, calculated relative to the value obtained with the same reporter in the absence of the respective TAp73-isoform or of p53. $\Delta \mathrm{Np} 73$ (a) and $\Delta 84 \mathrm{p} 73 \beta$ (a) were not able to transactivate the CD95 gene. Moreover, they act as dominant-negative being able to repress the ability of TAp73 to drive the CD95 gene. In addition to their ability to inhibit TAp73-mediated transactivation of the CD95 gene, the $\Delta \mathrm{N}$ - and $\Delta 84$ isoforms of p73 inhibit wt p53-induced transactivation of the CD95 gene (c). Assays were performed in triplicates in five independent experiments. One representative experiment is shown (mean \pm S.D., $n=3$ ). (d) $\Delta \mathrm{N}$ - and $\Delta 84$ isoforms of $p 73$ inhibit specific apoptosis induced by $\mathrm{TAp} 73 \beta$. Hep3B cells were transduced for $72 \mathrm{~h}$ either with $\mathrm{rAd}$ TAp73 $\beta$ (10 MOI) or rAd $\Delta 84 p 73 \beta$ (10 MOI). Data obtained in three separate experiments were averaged, presented is mean \pm S.D., $n=9$

apoptosis activity of TAp73 $\beta, \mathrm{N}$ terminus-deleted p73-isoforms exert their antiapoptotic action also on mitochondrial apoptosis signaling pathways.

\section{TAp73 $\beta$ sensitizes cancer cells towards chemotherapy}

p53 is frequently mutated in human cancer. This has been implicated in resistance towards chemotherapy. We therefore next investigated if $\mathrm{TAp} 73 \beta$ restores chemosensitivity of cancer cells.

First, we found that chemotherapeutic agents (bleomycin, mitoxantrone and doxorubicin) induce endogenous TAp73 expression in Hep3B cells (Figure 7a). This is in accordance with data obtained in other cell lines. ${ }^{19}$ We then tested if there is a synergistic effect of $\operatorname{TAp} 73 \beta$ and chemotherapeutic agents on the induction of cell death. We infected Hep3B (p53-/-), HepG2 (wt p53) AGS (wt p53) and Saos2 (p53-/-) cells with an adenoviral TAp73 $\beta$ (5 and $10 \mathrm{MOI}$ ). Then we exposed the cells to different doses of bleomycin. Figure $6 \mathrm{a}$ shows that rAd-TAp73 $\beta$ enhances cell killing by bleomycin. All 
cancer cell lines tested displayed an increased responsiveness towards cell death after adenoviral TAp73 $\beta$ transfer, independent of their p53 status. A balanced two-way analysis of variance (ANOVA) revealed a highly significant synergistic interaction $(P<0.0001)$ between TAp73 $\beta$ and bleomycin in induction of cell death.

The observed synergy of TAp73 $\beta$ and chemotherapeutic drugs was due to a cooperative effect on induction of specific apoptosis (Figure 6b). FACScan ${ }^{\circledR}$ analysis ${ }^{20}$ revealed that TAp73 $\beta$ significantly increased drug-induced apoptosis of Hep3B and Saos2 cells $(P<0.0001)$. DAPI staining also illustrated the cooperative effect on the induction of cell death (Figure 6c).

We further analyzed the mechanisms contributing to the enhanced chemosensitivity conferred by TAp73 $\beta$. The

a
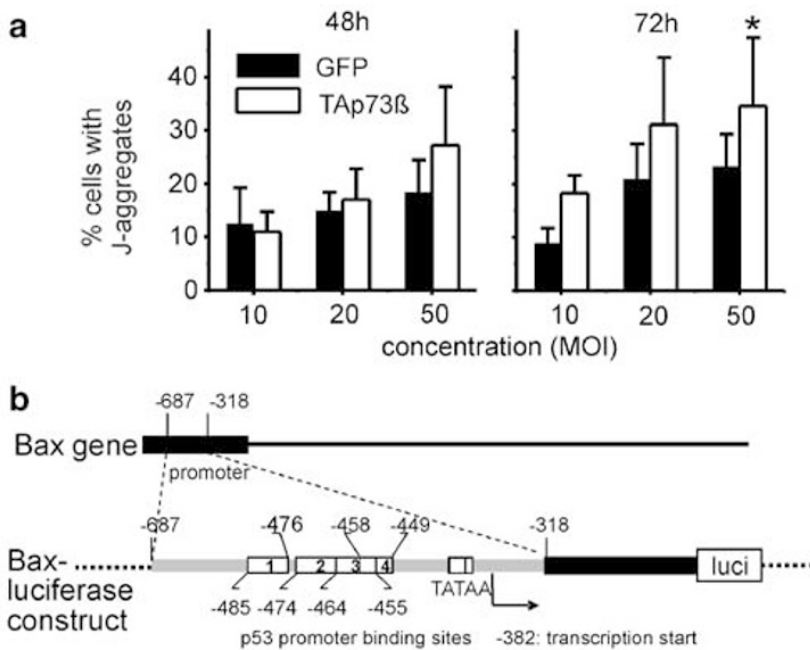

C

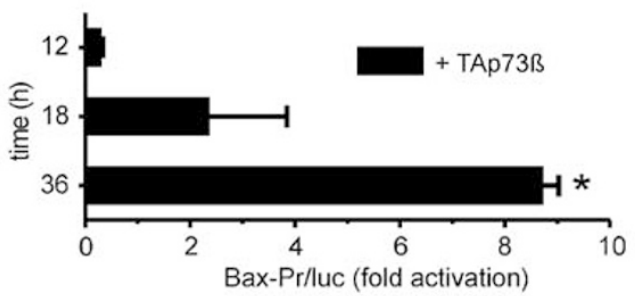

d
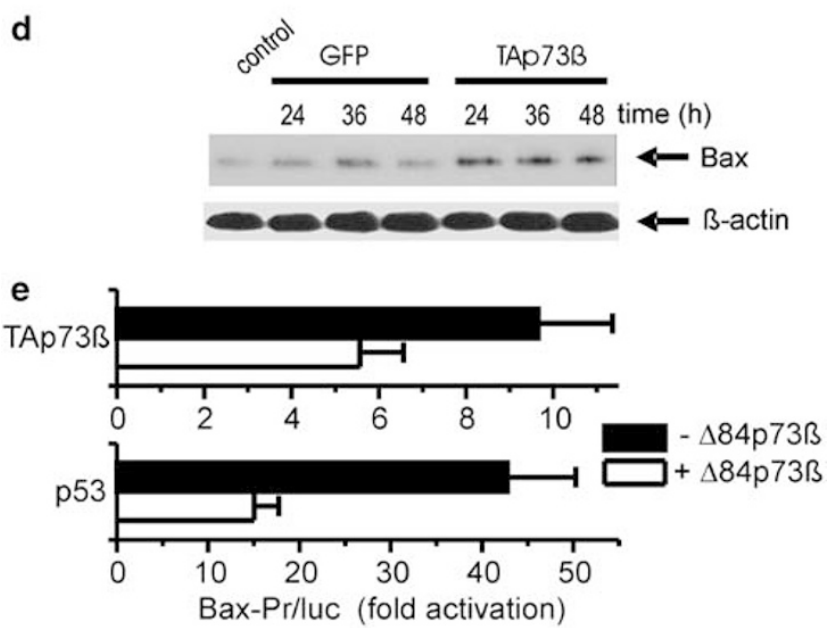

synergy of TAp73 $\beta$ and bleomycin turned out to be due to a cooperative action at different levels of apoptosis signaling, namely at the death receptor and the mitochondrial level, enhancing apoptosis mediated by the CD95 system (Figure $6 \mathrm{~d}$ and e) as well as apoptosis mediated by mitochondrial activation (Figures $6 f$ and $g$ and 7e). CD95 ligand mRNA was induced upon bleomycin treatment (Figure $6 \mathrm{~d}$ and reported previously, ${ }^{17,18,21}$ ) but not by $\operatorname{TAp} 73 \beta$, whereas TAp73 $\beta$ stimulated upregulation of CD95 receptor mRNA. Apoptosis following adenoviral TAp73 $\beta$-transfer and bleomycin treatment was partially blocked by an antagonistic anti-CD95L Ab (NOK-1), indicating a role of a CD95L/CD95 interaction in the death process (Figure 6e). Thus, the observed synergy of TAp73 $\beta$ and chemotherapy may in part result from enhanced CD95 expression (due to TAp73 $\beta$ ) triggered by upregulated CD95 ligand (due to chemotherapy). In addition, we show a cooperative action of $\operatorname{TAp} 73 \beta$ and bleomycin on mitochondrial apoptosis. FACScan ${ }^{\circledR}$ analysis showed that the change of the mitochondrial membrane potential caused by $\operatorname{TAp} 73 \beta$ was significantly increased by addition of bleomycin (Figure 7e). The cooperative action of $\operatorname{TAp} 73 \beta$ and bleomycin on mitochondrial apoptosis is further evidenced by the fact that combined treatment led to a significant increase of the transactivation of the Bax gene (Figure 6f). This was validated on protein level; combined treatment led to a further increase of endogenous Bax protein (Figure $6 \mathrm{~g}$ ).

\section{$\Delta$ Np73 confers drug resistance to p53-deficient tumor cells}

Since TAp73 and $\Delta$ Np73 show opposite effects on apoptosis induction, we investigated if $\Delta \mathrm{Np} 73$ interferes with chemotherapy-induced apoptosis.

Both, endogenous TAp73 and $\triangle \mathrm{Np} 73$ are upregulated in response to DNA damage by bleomycin, mitoxantrone and doxorubicin in Hep3B cells (Figure $7 \mathrm{a}$ and b). $\Delta 84 p 73 \beta$

Figure 5 TAp73 $\beta$ engages mitochondrial apoptosis pathways. (a) FACScan ${ }^{\circledR}$ analysis of Hep3B cells following JC-1 staining showed alteration of the mitochondrial membrane potential. After $72 \mathrm{~h}$, there was a significant increase in J-aggregates due to TAp73 $\beta$ (between-subject effect), which was significantly dose-dependent (within-subject effect). Data obtained in three separate experiments were averaged, presented is mean + S.D., $n=9$. ${ }^{\star} P<0.001$, MANOVA, between-subject effect; GFP versus TAp73 $\beta$, and $P<0.05$, MANOVA, within-subject effect; for $48 \mathrm{~h}: P=0.06$, MANOVA, between-subject effect. (b) Overview of the Bax-luciferase gene construct used in (c) containing a luciferase construct of the Bax promoter with its four p53 promoter binding-sites (white boxes). ${ }^{32} C$, TAp73 $\beta$ transactivates the Bax gene. Hep3B cells were transfected with $1 \mu \mathrm{g}$ of the reporter plasmid presented in (b) together with 10 MOI rAd-TAp73 $\beta$. The fold TAp73 $\beta$-dependent activation of the Bax-Pr/luc reporter plasmid, calculated relative to the value obtained with the same reporter in the absence of TAp73 $\beta$ is shown. TAp73 $\beta$ induced a significant timedependent increase of the transactivation of the Bax gene (ANOVA). A representative result of five independent experiments is shown. Presented is mean \pm S.D., $n=3$. ${ }^{\star} P<0.001$, ANOVA. (d) Immunoblot of endogenous Bax expression following $\mathrm{rAd}-\mathrm{TAp} 73 \beta$ transfer. (e) $\Delta \mathrm{Np73}$ and $\Delta 84 \mathrm{p73} \beta$ act as dominant-negative being able to repress the ability of p53 and TAp73 $\beta$ to transactivate the Bax gene. Presented is the fold TAp73 $\beta$ - or p53-dependent $(10 \mathrm{MOI})$ activation of the Bax-Pr/luc reporter plasmid $(1 \mu \mathrm{g})$, calculated relative to the value obtained with the same reporter in the absence of TAp73 $\beta$ or p53. Assays were performed in triplicates in three independent experiments. One representative experiment is shown (mean \pm S.D., $n=3$ ) 

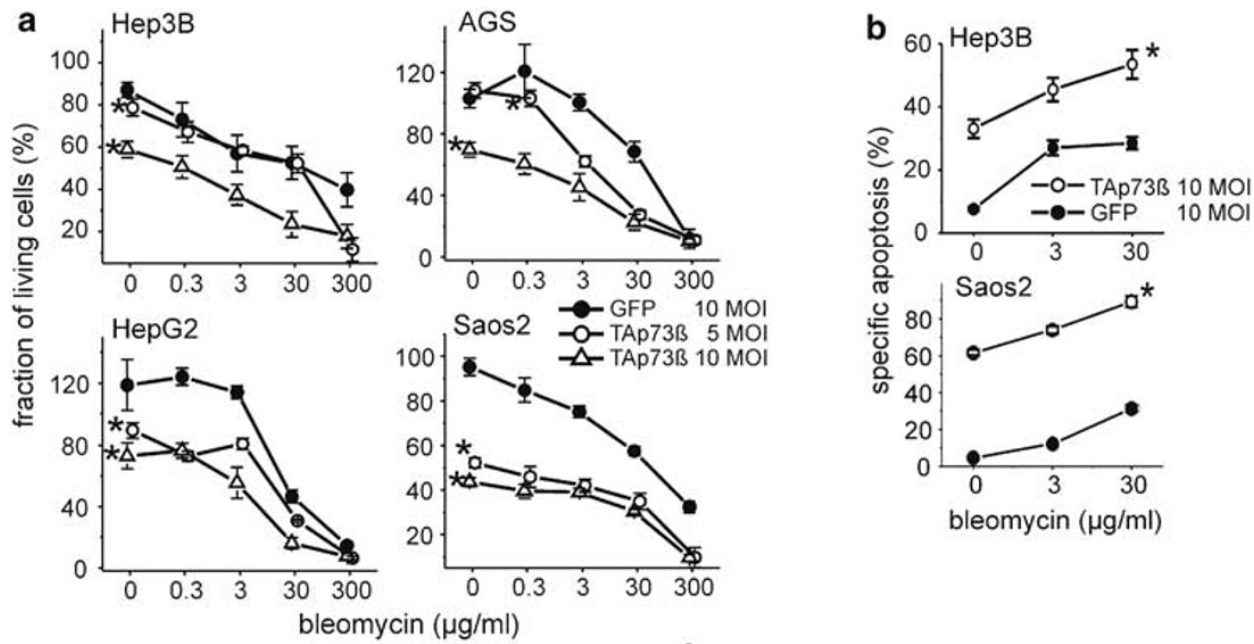

C

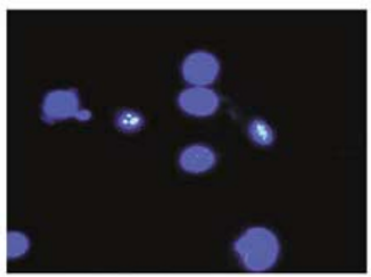

bleomycin

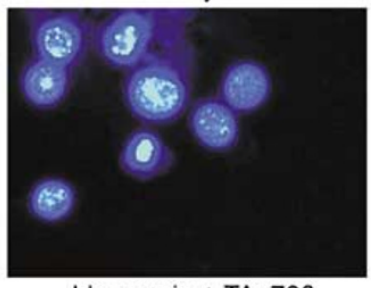

bleomycin + TAp73ß

f

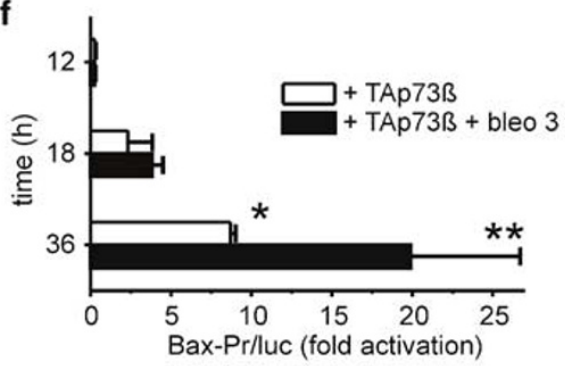

d

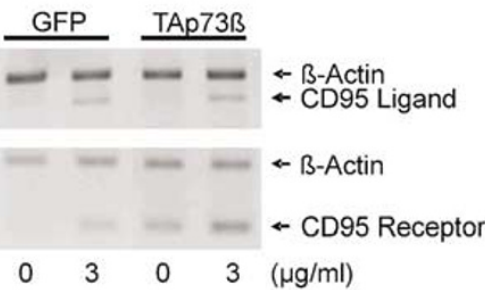

bleo $\begin{array}{lllll}0 & 3 & 0 & 3 & (\mu \mathrm{g} / \mathrm{ml})\end{array}$

e

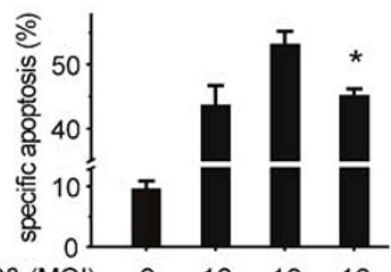

$\begin{array}{lllll}\text { TAp73ß (MOI) } & 0 & 10 & 10 & 10\end{array}$ bleo $(\mu \mathrm{g} / \mathrm{ml}) \quad 0 \quad 0030 \quad 30$ NOK-1 $(\mu \mathrm{g} / \mathrm{ml}) \quad 0 \quad 000010$

g

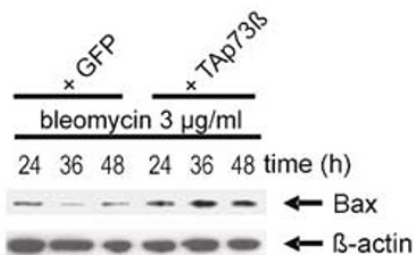

Figure 6 TAp73 $\beta$ sensitizes cancer cells towards chemotherapy. (a) TAp73 $\beta$ and chemotherapeutic agents synergize in the induction of cell death. All cell lines tested, independent of their p53 status, displayed an increased responsiveness towards cell death after adenoviral TAp73 $\beta$ transfer. A balanced two-way ANOVA revealed a synergistic interaction between TAp73 $\beta$ - and bleomycin-induced cell death for all cell lines tested $(P<0.0001)$. Data are expressed as the fraction of living cells, not treated with rAd-GFP or rAd-p73 $\beta$ or bleomycin (mean \pm S.D., $n=6$ wells). ${ }^{*}$ By MANOVA, between-subject effect $P<0.0001$ compared to GFP 10 MOI. (b) TAp73 $\beta$ significantly increased drug sensitivity of Hep3B and Saos2 cells. Thus, the increase in cell death shown in (a) is due to an increase in specific apoptosis. Data obtained in two separate experiments were averaged. * By MANOVA, between-subject effect $P<0.0001$, mean \pm S.D., $n=6$. (c) DAPI staining shows the synergistic effect of rAdTAp73 $\beta(10 \mathrm{MOI}$ ) and chemotherapeutic agents (bleomycin $3 \mu \mathrm{g} / \mathrm{ml}$ ) on the induction of cell death in Hep3B cells. (d) Enhanced chemosensitivity is partially due to a cooperative activation of the CD95 receptor/ligand system by TAp73 and anticancer drugs. Cytostatic treatment of Hep3B cells with bleomycin increased CD95 ligand mRNA expression. In contrast, rAd-TAp73 $\beta(10 \mathrm{MOI})$ transfer alone did not upregulate CD95 ligand mRNA. Moreover, Hep3B cells transduced with TAp73 $\beta$ responded with enhanced expression of CD95 receptor mRNA. (e) Apoptosis following adenoviral TAp73 $\beta$-transfer and bleomycin treatment was partially blocked by an antagonistic anti-CD95L Ab (NOK-1) in Hep3B cells. Data obtained in two separate experiments were averaged, presented is mean \pm S.D., $n=6$. ${ }^{\star} P<0.05$, Wilcoxon test, compared to the (next) left column. (f) The cooperative action of TAp73 $\beta$-transfer and chemotherapy leads to enhancement of Bax gene transactivation. Combined treatment with $3 \mu \mathrm{g} / \mathrm{ml}$ bleomycin led to a further increase of the transactivation of the Bax promoter. Treatment conditions are as detailed in Figure $5 \mathrm{c}$. One representative out of three experiments performed is shown, mean \pm S.D., $n=3$. ${ }^{*} P<0.001$, MANOVA, within-subject effect (time-effect), ${ }^{*} P<0.05$, MANOVA, between-subject effect (bleomycin-effect). (g) Western blot analysis confirms the cooperative induction of endogenous Bax protein by rAd-TAp73 $\beta$ and bleomycin in Hep3B cells 


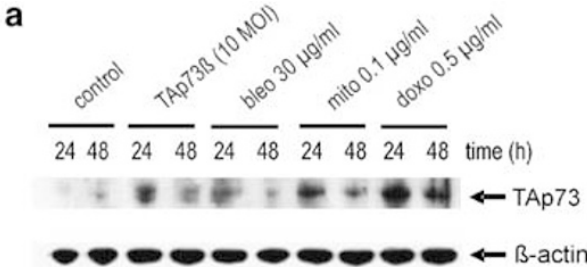

b

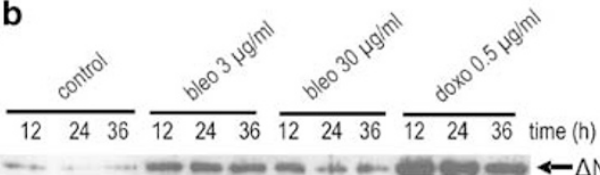

-. - - - - - - - - - -
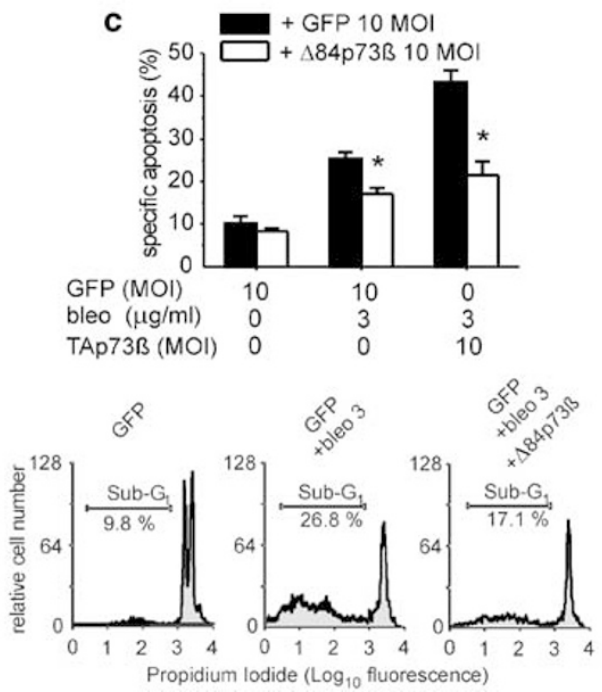

d
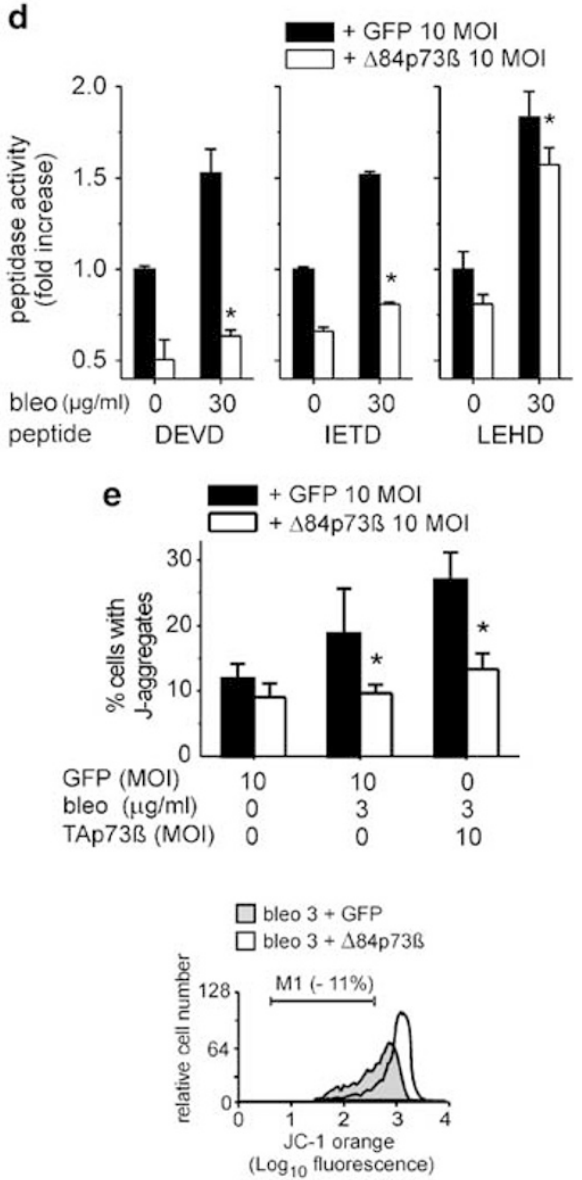

Figure 7 Blocking TAp73 function with a dominant-negative isoform, $\Delta 84 p 73 \beta$, confers chemotherapy resistance. (a, b) Western blot analysis showed upregulation of endogenous TAp73 and endogenous $\triangle$ Np73 following treatment of Hep3B cells with bleomycin, mitoxantrone or doxorubicin in clinically relevant concentrations. (c) Blocking TAp73 $\beta$ function with $\Delta 84 p 73 \beta$ inhibits chemotherapy-induced apoptosis. Hep3B cells transduced with $10 \mathrm{MOI}$ rAd- $\Delta 84 \mathrm{p} 73 \beta$ were treated with bleomycin for $72 \mathrm{~h}$. FACScan ${ }^{\mathbb{R}}$ analysis of propidium iodide-stained nuclei. One representative out of three experiments performed is shown, mean + S.D., $n=3 .{ }^{*} P<0.05$, Wilcoxon test, compared to the (next) left column. (d) Hep3B cells transduced with $10 \mathrm{MOI}$ rAd- $\Delta 84 \mathrm{p} 73 \beta$ or $10 \mathrm{MOI}$ rAd-GFP were treated with bleomycin and determination of the increased enzymatic activity of the caspase-3, -8 and -9 class of proteases was performed by fluorometric assays $48 \mathrm{~h}$ later. Fold activation represents the DEVDase(consistent with caspase 3-), IETDase- (consistent with caspase 8-) and LEHDase- (consistent with caspase 9-) activity compared to control cells, transduced with rAdGFP, only. One representative out of three experiments performed is shown, mean \pm S.D., $n=3$. ${ }^{*} P<0.05$, Wilcoxon test. (e) Blocking endogenous TAp73 with $\triangle 84 \mathrm{p} 73 \beta$ inhibits chemotherapy-induced apoptosis at the mitochondrial level. FACS analysis following JC-1 staining of Hep3B cells treated for $72 \mathrm{~h}$ revealed a significant change of the mitochondrial membrane potential following rAd-TAp73 $\beta$ transfer and/or bleomycin treatment, which was inhibited by $\Delta 84 p 73 \beta$. One representative out of three experiments performed is shown, mean \pm S.D., $n=3 .{ }^{*} P<0.05$, Wilcoxon test, compared to the (next) left column

counteracts specific apoptosis induced by $\operatorname{TAp73} \beta$ and bleomycin (Figure $7 \mathrm{c}$ ). Interference of $\Delta \mathrm{Np} 73$ with apoptosis sensitivity can take place at several levels of apoptosis signaling. As shown in Figure 4, $\Delta$ Np73 can directly interfere with the transcriptional activation function of p53 and TAp73 and consequently inhibit transactivation of the CD95 gene by p53 or TAp73. Furthermore, resistance towards chemotherapy by $\Delta \mathrm{Np} 73$ can be imposed at the caspase-, and the mitochondrial level of apoptosis signaling. Figure $7 \mathrm{~d}$ shows that $\mathrm{rAd}-\Delta 84 \mathrm{p} 73 \beta$ inhibits bleomycin-induced activation of caspase-3, -8 , and -9 class of proteases. Adenoviral transfer of $\Delta 84 \mathrm{p} 73 \beta$ strongly reduces mitochondrial activation induced by bleomycin and TAp73 $\beta$ as measured by Bax reporter assays and FACScan ${ }^{\circledR}$ analysis following $\mathrm{JC}-1$ staining (Figure $5 \mathrm{e}$ and $7 \mathrm{e}$ ). Repression of TAp73 $\beta$-mediated transactivation of the Bax promoter was one mechanism by which $\Delta \mathrm{Np} 73$ acts as dominant-negative on mitochondrial apoptosis signaling (Figure 5e). Even though we cannot exclude a direct activity of $\Delta \mathrm{Np} 73$ on the mitochondria, it is more likely that the effect of $\Delta N p 73$ on mitochondria is also due to its interference with TAp73-mediated transactivation, albeit other genes are involved (Table 1). This supports the hypothesis that the ratio of the two isoforms TAp73/ $\Delta \mathrm{Np} 73$ is an important determinant of clinical response to chemotherapy. This prompted us to further analyze the clinical significance of $\Delta \mathrm{Np} 73$ expression in patients with HCC.

\section{Clinical impact of $\Delta \mathrm{Np} 73$ overexpression: $\Delta \mathrm{Np} 73$ is a prognostic marker in patients with $\mathrm{HCC}$}

Western blot analysis revealed that TAp73 and $\Delta \mathrm{Np} 73$ are specifically expressed in tumor tissue, but not in nonneoplastic liver tissue. Hereby, TAp73 and $\Delta$ Np73 seemed 
to be inversely regulated, that is, high expression of TAp73 corresponded to low expression of $\Delta \mathrm{Np} 73$ and vice versa (Figure 8).

By immunostaining, our antibody raised specifically against $\Delta \mathrm{Np} 73$, identified 31 out of $84(37 \%)$ of the HCCs to overexpress $\Delta \mathrm{Np} 73$ (Table 2, Figure 9a and b). Within these tumors, we observed a strong immunoreactivity of the tumor cell nuclei. In the case of surrounding, non-neoplastic cirrhotic liver tissue, normal hepatocytes were seen to be occasionally positive for $\Delta \mathrm{Np} 73$. In contrast to the corresponding tumors, however, in nontumorous tissue only very few nuclei $(<1 \%)$ expressed $\Delta \mathrm{Np} 73$ (Figure 9c).

p53 mutational analysis revealed that $46 \%$ (39/84) of these HCC patients carried p53 mutations. There was no correlation between $\Delta \mathrm{Np} 73$ overexpression and the p53 mutational status (Table 3 ).

The survival analysis took into account $\Delta \mathrm{Np} 73$ positivity (defined by immunohistochemistry), UICC tumor stage and

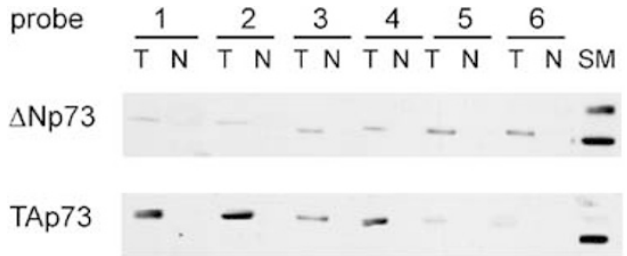

Figure 8 Western Blot analysis of $\triangle N p 73$ and TAp73 expression in six HCCs ('T') and corresponding non-neoplastic liver tissue ('N') using our specific antibodies. TAp73 and $\Delta \mathrm{Np} 73$ are distinctively expressed in tumor tissue, but not in non-neoplastic liver tissue

Table 2 HCC-patients and pathohistologic data ${ }^{a}$

\begin{tabular}{lccc}
\hline & $\begin{array}{c}\text { No. of } \\
\text { patients } \\
(\boldsymbol{n}=\mathbf{8 4})\end{array}$ & $\begin{array}{c}\text { Median survival } \\
\text { time (95\% CI), } \\
\text { days }\end{array}$ & $\boldsymbol{P}$ \\
\hline $\begin{array}{l}\text { Stage } \\
\text { Stage I }\end{array}$ & $10(12 \%)$ & $40(0-1035)$ & $P<0.05$ \\
Stage II & $21(25 \%)$ & $739(0-2056)$ & $\begin{array}{c}\text { Stage I/II vs } \\
\text { Stage III }\end{array}$ \\
Stage IIIA & $32(38 \%)$ & $360(115-548)$ & \\
Stage IIIB & $14(17 \%)$ & $111(27-185)$ & \\
Stage IIIC & $7(8 \%)$ & $241(70-430)$ & \\
pT category & & & \\
pT1 & $10(12 \%)$ & $40(0-1035)$ & \\
pT2 & $21(25 \%)$ & $359(141-2056)$ & \\
pT3 & $36(43 \%)$ & $269(60-548)$ & \\
pT4 & $17(20 \%)$ & $273(144-430)$ & \\
& & & \\
Edmondson grading & & \\
G1 & $19(23 \%)$ & $431(112-530)$ & \\
G2 & $36(43 \%)$ & $310(48-709)$ & \\
G3 & $25(30 \%)$ & $127(54-210)$ & \\
G4 & $4(5 \%)$ & $123(52-198)$ & \\
ANp73 overexpression & & & \\
Present & $31(37 \%)$ & $168(78-260)$ & \\
Absent & $53(63 \%)$ & $491(210-915)$ & \\
& & & \\
\hline
\end{tabular}

${ }^{a} 95 \% \mathrm{Cl}=95 \%$ confidence interval; pT category = primary tumor category; $\mathrm{NS}=$ not statistically significant. $P$-values are two-sided (log-rank test). ${ }^{\mathrm{b}} \mathrm{See}$ Sobin and Wittekind. ${ }^{36}$ See Hamilton and Aaltonen. ${ }^{35}$ dUsing our specific $\Delta$ Np73 antibody ${ }^{30}$
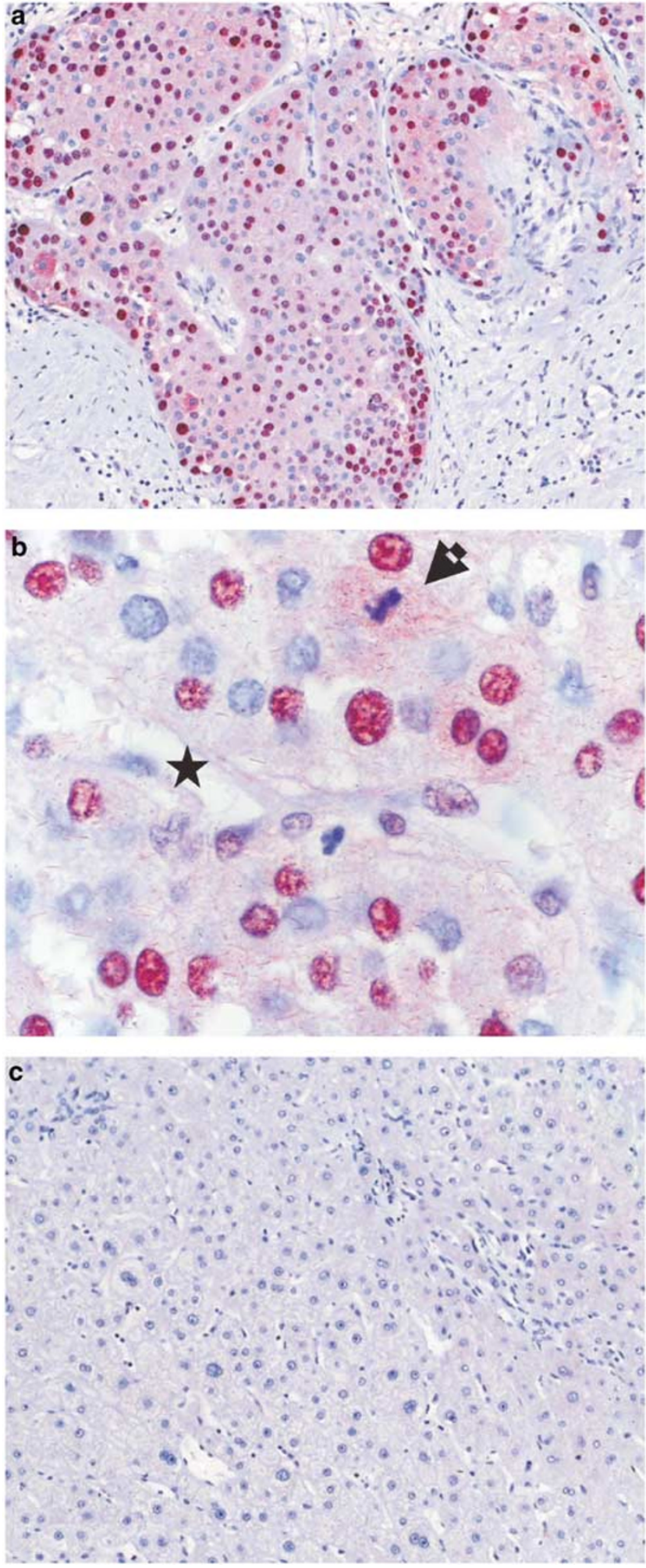

Figure 9 Immunohistochemical demonstration of $\Delta \mathrm{Np} 73$ protein in hepatocellular carcinoma and in non-neoplastic liver tissue using our specific antibody. ${ }^{30}$ (a) $\Delta$ Np73 staining signal is localized within tumor cell nuclei (red reaction product; original magnification $\times 20$ ). (b) Positive tumor cell nuclei with a slight perinuclear staining during mitosis (arrowhead): $\Delta$ Np73 immunoreactivity occurs also in the cytoplasm. Sinus endothelial cells are $\Delta$ Np73-negative (asterisk) (original magnification $\times 100$; oil immersion). (c) Surrounding liver tissue is negative for $\Delta \mathrm{Np} 73$ (original magnification $\times 20$ ) 
Table 3 Correlation of p53 mutational status and expression of $\triangle \mathrm{Np} 73$ in $\mathrm{HCC}^{\mathrm{a}}$

\begin{tabular}{lccc}
\hline & $\Delta$ Np73 positive & $\Delta$ Np73 negative \\
\hline Mutant p53 & 18 & 21 & $39(46 \%)$ \\
Wild-type p53 & 13 & 32 & $45(54 \%)$ \\
& $31(37 \%)$ & $53(63 \%)$ & $84(100 \%)$ \\
\hline
\end{tabular}

${ }^{a}$ Not statistically significant, Fisher's exact test two-sided

Edmondson grade. Consistent with published data, UICC stage and Edmondson grade were valuable prognostic parameters (Table 2). Of clinical importance is our finding of a significantly shorter survival time of patients with tumors overexpressing $\Delta \mathrm{Np} 73$ compared to patients whose tumors were $\Delta$ Np73 negative $(P<0.005$, log-rank test) (Table 2)

\section{Discussion}

Findings obtained in the present study allow us to propose a model that links the regulation of apoptosis by the relative expression of TAp73 and $\triangle \mathrm{Np} 73$ to chemosensitivity and clinical outcome in HCC (Figure 10). Our data provide three new findings: (1) the identification of new target genes of TAp73/ANp73-regulated apoptosis pathways, (2) the molecular mechanisms of TAp73/ $\Delta \mathrm{Np} 73$ in chemosensitivity and (3) the characterization of $\Delta \mathrm{Np} 73$ as a new prognostic marker for patients with HCC.

Our results support a two-pathway model for the TAp73apoptotic response in hepatoma cells. Here, we show that TAp73 $\beta$ is involved in the activation of both, the extrinsic/ death receptor-mediated apoptosis pathway as well as the intrinsic/mitochondria-mediated apoptosis pathway, pathways 1 and 2, respectively (Table 1 and Figure 10).

TAp73 $\beta$ can trigger each of the major death receptor systems, the CD95-, the TNF-R- and the TRAIL-R-system. We identified the CD95 gene as a transcriptional target of TAp73 $\beta$ via the intronic p53 enhancer. We show that TAp73dependent transactivation of the CD95 gene depends on the intronic p53 binding site, as it was totally abrogated when we mutated the intronic p53-binding site of the CD95 gene. The TRAIL-R1 and -R2 genes are other death receptor genes that harbor p53-binding elements. ${ }^{22,23}$ Thus, TAp73 $\beta$-mediated transcriptional activation of the TRAIL-R1 and -R2 genes might also be exerted via binding to p53-responsive elements. Furthermore, we found TNF-R1 and TNF to be upregulated by TAp73 $\beta$. This is in line with recent findings that C-ABL and p73 contribute to apoptosis induced by $\mathrm{TNF} \alpha$, in addition to their role in promoting DNA damage-associated cell death. ${ }^{24}$ As for the CD95 system, CD95 ligand mRNA was induced upon concomitant treatment with cytostatic drugs but not by TAp73 $\beta$ alone. Thus, TAp73-mediated increases in CD95 expression may lead to apoptosis in a CD95 ligandindependent fashion. Spontaneous multimerizing of overexpressed CD95 and TNFR1 has been reported previously to result in the induction of CD95- and TNF-like effects, independent of the respective ligand, suggesting that the self-association of the death domain suffices to trigger downstream signaling and apoptosis. ${ }^{25,26}$

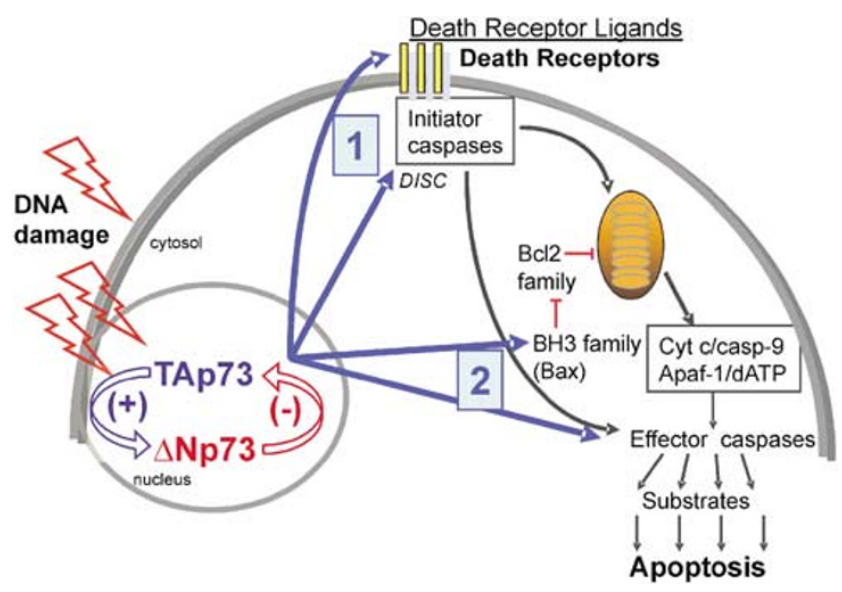

Figure 10 Model of TAp73/ANp73-regulated apoptosis. Upon DNA damage, TAp73 activates both, the death receptor- (pathway 1) and the mitochondrial(pathway 2) apoptosis pathway. $\Delta \mathrm{Np} 73$ is a strong inhibitor of both pathways

In addition to its direct effect on death receptor-mediated apoptosis, TAp73 $\beta$ can contribute to apoptosis by inducing the expression of several pro-apoptotic proteins acting at the mitochondrial level. Using microarray analysis we identified BAD, BIK, BNIP3, HRK and RAD9 to be upregulated in cells overexpressing TAp73 $\beta$. Similar to p53, TAp73 was able to transactivate the Bax promoter in hepatoma cells and to induce an increase of endogenous Bax protein levels. This is in line with previous findings from our group in a different cellular system (Saos2 cells). ${ }^{27}$ Thus, TAp73, like p53, ${ }^{1}$ engages the major apoptotic pathways in the cell stimulating both death receptor signaling and apoptosis emanating from mitochondria.

Furthermore, our results show a relevant role for TP73 in chemosensitivity. Both, endogenous TAp73 and $\Delta$ Np73, are upregulated in response to DNA damage by bleomycin, mitoxantrone and doxorubicin. TAp73 $\beta$ significantly enhances the apoptosis-inducing effect of chemotherapeutic drugs in a variety of solid cancer cell lines. On the contrary, the $\mathrm{N}$ terminus-deleted p73 isoform predominantly detected in cancer, $\Delta 84 \mathrm{p} 73$, as well as the isoform produced by the second promoter, $\Delta \mathrm{Np} 73$, confers drug resistance to hepatoma cells. Interference of $\Delta \mathrm{Np} 73$ with death by apoptosis in tumor cells after treatment with anticancer agents can take place at several levels of apoptosis signaling. Resistance towards chemotherapy imposed by $\Delta \mathrm{Np} 73$ occurred at least in part by downregulation of the CD95 gene. Our data show that direct interference with the CD95 gene transactivation function of TAp73 and of p53 is one molecular mechanism by which $\triangle \mathrm{Np} 73$ exerts its antiapoptotic and oncogenic function. ${ }^{8,10,28}$ This inhibitory effect of $\Delta N p 73$ is not restricted to the CD95 gene. There may exist additional proapoptotic genes (harboring p53 binding elements) whose expression is downregulated by $\Delta \mathrm{Np} 73$, contributing to tumor progression and a worse patient outcome. We identified the Bax promoter to be repressed by $\Delta \mathrm{Np} 73$. Thus, resistance towards apoptosis by $\Delta \mathrm{Np} 73$ is also imposed by inhibition of mitochondrial apoptosis pathways. Furthermore, $\Delta N p 73$ strongly inhibited chemotherapy-induced activation of caspase-3, -8 and -9 . Of note, our data couple the disruption of apoptosis at the death receptor- and mitochondrial level by 
$\Delta$ Np73 with intrinsic drug resistance. We show that the functional status of TAp73/ $\triangle \mathrm{Np} 73$ is an important determinant of cellular response to chemotherapeutic drugs. While the expression of TAp73 synergizes with chemotherapeutic drugs, the protein isoform $\Delta \mathrm{Np} 73$ confers drug resistance. This implies that the natural, or pharmacologically regulated, relative balance of these two isoforms may influence the clinical outcome.

Emerging evidence from the analysis of primary human tumors shows that deregulated $\Delta \mathrm{Np} 73$ expression is rather frequent. $^{8,9}$ In neuroblastoma, which is almost exclusively wild-type for $\mathrm{p} 53$, a correlation of $\Delta \mathrm{Np} 73$ status with the clinical outcome was seen. ${ }^{9}$

In a series of 193 patients with HCC, we have previously shown detectable (high) p73 by in situ hybridization and immunohistochemistry in $32 \%$ of the tumors, whereas all normal tissue had undetectable p73 levels. ${ }^{29}$ Many of the (early) p73 overexpression studies in human cancers determined total $p 73$ levels, because the antibodies used could not distinguish between $\mathrm{TA}$ and $\Delta \mathrm{Np} 73$. We have generated highly specific antibodies ${ }^{30}$ and we show here for the first time that it is the $\Delta \mathrm{Np} 73$ isoform, which is upregulated in HCC. Our antibody raised specifically against $\Delta \mathrm{Np} 73$, identified 31 out of $84(37 \%)$ of patients with HCC to overexpress $\Delta N p 73$ in their tumor tissue. Importantly, we provide the first evidence that $\triangle \mathrm{Np} 73$ upregulation in $\mathrm{HCC}$ is correlated with a poor prognosis. Patients with tumors overexpressing $\Delta \mathrm{Np} 73$ exhibited a significantly shorter survival time compared with patients whose tumors were $\Delta$ Np73 negative $(P<0.005$ logrank test). This is an important and clinically relevant finding, which suggests the use of $\Delta \mathrm{Np} 73$ status as a prognostic marker for patients with HCC.

Our finding that a significant percentage of HCCs select for dominant-negative p73 isoforms strongly argues for their oncogenic role during hepatocarcinogenesis. Preferential upregulation of $\triangle \mathrm{Np} 73$ in HCCs might impose oncogenic activity that specifically interferes with the tumor suppressor function of wild-type p53 and TAp73 disabling major apoptosis pathways (death receptor- and mitochondrial pathways), as we have shown in vitro.

Molecular links between apoptosis, tumorigenesis and drug resistance provide the foundation for new therapeutic approaches and for a targeted cancer therapy. Our results show that $\mathrm{p} 53$ is not the only component in predicting prognosis and response to chemotherapy, but instead the status of a network that contains p53, p73 and p63. ${ }^{14}$ Therapeutic modulation of TAp73/ $\mathrm{Np} 73$ and mutant $\mathrm{p} 53$ levels might be used to target the large percentage of human tumors that harbor $\mathrm{p} 53$ mutations and/or overexpress $\Delta \mathrm{Np} 73$. One might predict that interfering with the expression or function of $\Delta \mathrm{Np} 73$ and/or mutant p53 and/or $\Delta \mathrm{Np} 63$ in tumor cells may render such tumors more responsive to therapy and reduce their aggressiveness and metastatic capacity.

\section{Materials and Methods}

\section{Cell lines}

We used Hep3B (human liver carcinoma, deficient in p53 [p53-/-]), HepG2 (human hepatoblastoma, wild-type (wt) p53), AGS (human gastric adenocarcinoma, wt p53) and Saos2 (human osteosarcoma, p53-/-). Hep3B cells were maintained in MEM (Invitrogen, Karlsruhe, Germany), HepG2 and AGS in DMEM (Gibco BRL, Eggenstein, Germany) and Saos2 in a 1:1 mixture of Ham's F-12/DMEM (Biochrom, Berlin, Germany). Medium was supplemented with $10 \%$ FCS (Biochrom), $10 \mathrm{mM} \mathrm{HEPES} \mathrm{pH}$ 7.3 (Invitrogen), $2 \mathrm{mM} \mathrm{L-Glutamine} \mathrm{(Invitrogen)} \mathrm{and} 100 \mu \mathrm{g} / \mathrm{ml}$ Gentamycin (Invitrogen).

\section{Treatment with cytostatic drugs}

Cells were treated with bleomycin at a dose range of $0.3-300 \mu \mathrm{g} / \mathrm{ml}$ or with doxorubicin at a dose range of $0.005-0.5 \mu \mathrm{g} / \mathrm{ml}$ or with mitoxantrone at a dose range of $0.1-1 \mu \mathrm{g} / \mathrm{ml}$ for $6 \mathrm{~h}$ up to $72 \mathrm{~h}$. The concentrations relevant for therapy are $1.5-3 \mu \mathrm{g} / \mathrm{ml}$ for bleomycin, $0.001-0.02 \mu \mathrm{g} / \mathrm{ml}$ for doxorubicin, and $0.03-0.5 \mu \mathrm{g} / \mathrm{ml}$ for mitoxantrone in patients' sera.

\section{Treatment with IgG3 anti-APO-1}

The CD95 (Apo-1/Fas) receptor was stimulated with the monoclonal antibody anti-APO-1 lgG3, $\kappa$, at a concentration of $1 \mu \mathrm{g} / \mathrm{ml}$ as described. ${ }^{18}$

\section{Adenoviral constructs and transduction}

Replication deficient adenoviral vectors were generated according to the method of $\mathrm{He}$ et al. ${ }^{31}$ The vectors either encoded the complete human wt p53 cDNA (rAd-p53), TAp73 $\beta$ cDNA (rAd-TAp73 $\beta$ ) or $\triangle 84$ p73 $\beta$ cDNA $(\mathrm{rAd}-\Delta 84 \mathrm{p} 73 \beta)$, together with the GFP, or the GFP alone (rAd-GFP), each under the control of the cytomegalovirus immediate/early gene (CMV) promoter. At a $\mathrm{MOI}$ of 10 , an infection rate of $80-90 \%$ of the cells was obtained. Cells were seeded in six-well plates $24 \mathrm{~h}$ before transduction. Then adenoviruses ( $r A d-G F P, r A d-p 53, \operatorname{rAd}-T A p 73 \beta$ or $\operatorname{rAd}-\Delta 84 p 73 \beta$ ) were added to the culture medium and cells were incubated with the virus for $4 \mathrm{~h}$.

\section{Plasmids}

A construct was generated containing $3.2 \mathrm{~kb}$ of the physiological sequence of the CD95 gene, that is, the $3^{\prime}$ part of the promoter, the complete exon 1 and the $5^{\prime}$ part of intron 1. This plasmid is denoted p1142CD95-luc and has been employed in all the transient transfection assays presented. Mutants of the intronic p53-binding site of p1142CD95-luc ${ }^{18}$ were established using the QuickChange Site-Directed Mutagenesis Kit (Stratagene, Heidelberg, Germany).

The Bax-luciferase reporter plasmid (Bax-Pr/luc) and TAp73 $\alpha, \beta, \gamma, \delta$; $\Delta \mathrm{Np} 73 \beta$ and $\Delta 84 \mathrm{p} 73 \beta$ have been described previously. $7,32,33$

\section{Transfections}

Cells were transfected by the use of calcium-phosphate. After $18 \mathrm{~h}$ medium was changed. After $2 \mathrm{~h}$, cells were infected with the adenovirus at a $\mathrm{MOI}$ of 10 . After $24 \mathrm{~h}$, cells were harvested and assayed for luciferase activity as described by the manufacturer (Promega, Heidelberg, Germany).

\section{DAPI staining}

DAPI (4',6-diamidino-2-phenylindole, Sigma, Munich, Germany) staining of cellular DNA, was performed as described. ${ }^{17}$ 


\section{Cytotoxicity MTT-assay}

Cell viability was determined by a colorimetric MTT-assay as described. ${ }^{17}$

\section{Detection of apoptosis}

Apoptosis was assessed by fluorescence-activated cell sorting (FACS) analysis carried out in a FACScan ${ }^{\circledR}$ flow cytometer (Becton Dickinson, Heidelberg, Germany) using the CELLQuest ${ }^{\mathbb{R}}$ software system. Quantification of DNA fragmentation was performed by FACS analysis of propidium iodide-stained nuclei. ${ }^{18,20}$

To block apoptosis, the broad spectrum caspase inhibitor ZVAD-FMK (z-Val-Ala-DL-Asp-fluoromethylketone, Bachem, Bubendorf, Germany), DEVD-FMK (Z-Asp(OCH3)-Glu(OCH3)-Val-Asp(OCH3)-FMK; inhibitor of caspase-3 as well as -6, -7, -8, and -10), Z-IETD-FMK (z-lle-Glu(OMe)Thr-Asp(OMe)-CH2F; inhibitor of caspase-8), Z-LEHD-FMK (z-LeuGlu(OMe)-His-Asp(OMe)-CH2F; inhibitor of caspase-9, also -4 and -5 ) (all from Calbiochem, Schwalbach, Germany) and the antagonistic antihuman CD95L mAb (clone NOK-1, BD Biosciences, Heidelberg, Germany) were applied.

For caspase fluorometric assays, Hep3B cells were harvested 36 and $48 \mathrm{~h}$ following rAd-TAp73 $\beta$ or rAd- $\Delta 84 \mathrm{p} 73 \beta$ or rAd-GFP transfer with or without concomitant bleomycin treatment (caspase-3, -8 and -9 fluorometric assay, R\&D systems, Minneapolis, MN, USA).

\section{Detection of CD95 ligand (CD95L) and CD95 receptor (CD95) mRNA}

Total cellular RNA was prepared from $3 \times 10^{6}$ cells treated with bleomycin and/or $10 \mathrm{MOI}$ rAd-TAp73 $\beta$, using the Rneasy-kit ${ }^{\circledR}$ (Qiagen, Hilden, Germany). PCR conditions and primers have been described previously. ${ }^{17,18}$

\section{Detection of CD95 (APO-1/Fas)}

Cell surface expression of the CD95 receptor was assessed by FACScan ${ }^{\circledR}$. Hep3B or Saos2 cells were incubated for 30 min with antiCD95 receptor antibody (anti-APO-1 $\operatorname{lgG} 3, \kappa$ ) and washed with PBS $\left(+10 \%\right.$ FCS). PE-labeled affinity purified $F(a b)_{2}$, fragment goat antimouse IgG Fc antibody (Dianova, Hamburg, Germany) was used as secondary detecting reagent. To examine staining specificity of the second antibody cells were incubated with isotype control (lgG3) alone.

\section{Immunodetection of Bax, TAp73 and $\triangle \mathrm{Np73}$}

For immunodetection of Bax, we applied the mouse anti-Bax monoclonal antibody sc-7480 (Santa Cruz Biotechnology, Inc., Santa Cruz, CA, USA). For the analysis of TAp73 and $\triangle N p 73$ expression in hepatoma cells and in liver tissue from patients with HCC, we used highly specific antibodies raised in rabbits against Sam and $\Delta \mathrm{N}$ domains, see below 'Immunohistochemical analysis and Western blot of tissue samples'. ${ }^{30}$

\section{Determination of mitochondrial membrane potential}

Hep3B cells were incubated with 5,5',6,6'-tetrachloro-1, $1^{\prime}, 3,3^{\prime}$-tetraethylbenzimidazolylcarbocyanine iodide (JC-1, $5 \mu \mathrm{g} / \mathrm{ml}$; Molecular Probes, Eugene, OR, USA) for $20 \mathrm{~min}$ at room temperature in the dark, washed twice and analyzed by FACScan ${ }^{\circledR}$ as described. ${ }^{14}$

\section{Microarray analysis}

We have developed high-density cDNA arrays in cooperation with the Department of Molecular Genome Analysis, German Cancer Research Center, Heidelberg, Germany. Hep3B cells were infected with $10 \mathrm{MOI}$ rAd-TAp73 $\beta$ or rAd-GFP respectively, and RNA was extracted after 12, 24, 36 and $48 \mathrm{~h}$ using the Quiagen RNAeasy-kit (Hilden, Germany). Two independent experiments were performed. Extracted RNA was checked for quality using Agilent 2100 bioanalyzer (Ambion, Waldbronn, Germany). Total RNA was labeled and rewritten to CDNA in a reverse transcriptase reaction, containing $100 \mathrm{ng} / \mathrm{ml}$ oligodT15 primer, $5 \mathrm{mmol}$ DTT, $1 \mathrm{mmol}$ of dATP, dDTP, dGTP and [33P]dCTP (Amersham, Freiburg, Germany) and $10 \mathrm{U}$ superscript II reverse transcriptase (Gibco BRL, Eggenstein, Germany). cDNA was hybridized to nylon membranes containing PCR-products of 1066 specific CDNA clones. These clones represent genes that are involved in apoptosis and immunological signaling pathways. In total, 36 clones, of which three representative clones are shown in Table 1, served as positive controls. Array preparation and quality control was performed by the German Resource Center for Genome Research (RZPD, Berlin/ Heidelberg, Germany). These arrays are now commercially available at www.rzpd.de (Immunofilter, RZPD). Hybridization was performed overnight at $68^{\circ} \mathrm{C}$ in Expresshyb ${ }^{\circledR}$ hybridization solution (Clontech, Heidelberg, Germany). Three hybridizations were performed for each experiment. After washing for $1 \mathrm{~h}$ in SDS-SSC buffer, arrays were exposed to phosphoimager screens and subsequently analyzed using a FujiBas ${ }^{\circledR}$ phosphoimager. We used Visual Grid Software (GPC Biotechnology, Martinsried, Germany) for matching the files. Expression levels were normalized over all positive spots using J-Express ${ }^{\circledR}$ software (J-Express V2.1, Molmine bioinformatics software solutions, Bergen, Norway) and subsequently evaluated by SAM (significance analysis of microarrays) software, which identifies genes whose expression has significantly changed. ${ }^{34}$

\section{Patients and tissue samples}

In total, 84 patients with HCC undergoing partial hepatectomy were included in a retrospective study. All patients underwent surgery with curative intent (R0 resections). Patients who received orthotopic liver transplantation were excluded from the study. No patient received preoperative or adjuvant chemotherapy or radiotherapy. Each tumor was evaluated with regard to typing, staging and Edmondson grading. Tumor typing and staging were performed by use of criteria of the World Health Organization $^{35}$ and the International Union Against Cancer (UICC), ${ }^{36}$ respectively. The patients and their pathohistological data are summarized in Table 2. The slides were evaluated by two observers who were blinded to clinical and pathologic information.

\section{Immunohistochemical analysis and Western blot of tissue samples}

We have generated new antibodies with p73 isoform specificity, recognizing only the TA domain of $p 73$ or only $\Delta \mathrm{N}$ isoforms. ${ }^{30}$

The rabbit polyclonal antibody against $\Delta N p 73$ was used for immunohistochemical analysis of $84 \mathrm{HCCs}$ and corresponding nonneoplastic liver tissue as described before. ${ }^{29}$

Western blot was performed using the rabbit polyclonal antibody against $\Delta \mathrm{Np} 73$ and the monoclonal antibody against the TA domain of p73 as described previously. ${ }^{37}$ 


\section{Statistical analysis}

To examine whether synergy between rAd-TAp73 $\beta$ transfer and concurrent chemotherapeutic treatment is observed, a balanced twoway ANOVA (model with fixed effects) was performed. Furthermore, we applied MANOVA (multivariate analysis of variance) and Wilcoxon analysis to test for statistical significance. The log-rank test was used to detect differences between survival curves for stratified variables. Statistical analysis was carried out using the SAS software system (SAS Institute Inc., Cary, NC, USA).

\section{Acknowledgements}

We thank Petra Hill for expert technical assistance. This work was supported by grants of the Medizinische Forschungsförderung Heidelberg, of the Sonderforschungsbereich 601 and of the Tumorzentrum Heidelberg/Mannheim to MM and PHK. The work was in part performed thanks to grants from AIRC, EU (QLG1-1999-00739 and YLK-CT-2002-01956), MIUR, MinSan to GM, EU (QLK3-CT-2002-01956) to GM and MO and EU grant QLG1-1999-00739 to PHK.

\section{References}

1. Vousden KH and Lu X (2002) Live or let die: the cell's response to p53. Nat. Rev. Cancer 2: 594-604

2. Melino G, De Laurenzi V and Vousden KH (2002) p73: friend or foe in tumorigenesis. Nat. Rev. Cancer 2: 605-615

3. Moll UM and Slade N (2004) p63 and p73: roles in development and tumor formation. Mol. Cancer Res. 2: 371-386

4. Ramadan S, Terrinoni A, Catani MV, Sayan AE, Knight RA, Mueller M, Krammer PH, Melino G and Candi E (2005) p73 induces apoptosis by different mechanisms. Biochem. Biophys. Res. Commun. 331: 713-717

5. Yang A, Walker N, Bronson R, Kaghad M, Oosterwegel M, Bonnin J, Vagner C, Bonnet H, Dikkes P, Sharpe A, McKeon F and Caput D (2000) p73-deficient mice have neurological, pheromonal and inflammatory defects but lack spontaneous tumours. Nature 404: 99-103

6. Kaghad M, Bonnet H, Yang A, Creancier L, Biscan JC, Valent A, Minty A, Chalon P, Lelias JM, Dumont X, Ferrara P, McKeon F and Caput D (1997) Monoallelically expressed gene related to $p 53$ at $1 p 36$, a region frequently deleted in neuroblastoma and other human cancers. Cell 90: 809-819

7. De Laurenzi V, Costanzo A, Barcaroli D, Terrinoni A and Falco M (1998) Two new p73 splice variants, gamma and delta, with different transcriptional activities. J. Exp. Med. 188: 1768

8. Zaika AI, Slade N, Erster SH, Sansome C, Joseph TW, Pearl M, Chalas E and Moll UM (2002) DeltaNp73, a dominant-negative inhibitor of wild-type p53 and TAp73, is up-regulated in human tumors. J. Exp. Med. 196: 765-780

9. Casciano I, Mazzocco K, Boni L, Pagnan G, Banelli B, Allemanni G, Ponzoni M, Tonini GP and Romani M (2002) Expression of DeltaNp73 is a molecular marker for adverse outcome in neuroblastoma patients. Cell Death Differ. 9: 246-251

10. Petrenko O, Zaika A and Moll UM (2003) DNp73 facilitates cell immortalization and cooperates with oncogenic Ras in cellular transformation in vivo. Mol. Cell. Biol. 23: $5540-5555$

11. Flores ER, Sengupta S, Miller JB, Newman JJ, Bronson R, Crowley D, Yang A, McKeon $\mathrm{F}$ and Jacks $\mathrm{T}$ (2005) Tumor predisposition in mice mutant for $\mathrm{p} 63$ and p73: evidence for broader tumor suppressor functions for the p53 family. Cancer Cell 7: 363-373

12. Agami R, Blandino G, Oren M and Shaul $Y$ (1999) Interaction of c-Abl and p73alpha and their collaboration to induce apoptosis. Nature 399: 809

13. Gong JG, Costanzo A, Yang HQ, Melino G, Kaelin Jr WG, Levrero M and Wang JY (1999) The tyrosine kinase c-Abl regulates p73 in apoptotic response to cisplatin-induced DNA damage. Nature 399: 806-809

14. Gressner $O$, Schilling T, Lorenz K, Schulze SE, Koch A, Schulze-Bergkamen $H$, Maria LA, Candi E, Terrinoni A, Valeria CM, Oren M, Melino G,
Krammer PH, Stremmel W and Müller M (2005) TAp63alpha induces apoptosis by activating signaling via death receptors and mitochondria. EMBO J. 24: 2458-2471

15. Flores ER, Tsai KY, Crowley D, Sengupta S, Yang A, McKeon F and Jacks $T$ (2002) p63 and p73 are required for p53-dependent apoptosis in response to DNA damage. Nature 416: 560-564

16. Senoo M, Manis JP, Alt FW and McKeon F (2004) p63 and p73 are not required for the development and p53-dependent apoptosis of T cells. Cancer Cell 6: 85-89

17. Müller $M$, Strand $S$, Hug $H$, Heinemann EM, Walczak $H$, Hofmann WJ, Stremmel W, Krammer PH and Galle PR (1997) Drug-induced apoptosis in hepatoma cells is mediated by the CD95 (APO-1/Fas) receptor/ligand system and involves activation of wild-type p53. J. Clin. Invest. 99: 403-413

18. Müller M, Wilder S, Bannasch D, Israeli D, Lehlbach K, Li-Weber M, Friedman SL, Galle PR, Stremmel W, Oren M and Krammer PH (1998) p53 activates the CD95 (APO-1/Fas) gene in response to DNA damage by anticancer drugs. J. Exp. Med. 188: 2033-2045

19. Irwin MS, Kondo K, Marin MC, Cheng LS, Hahn WC and Kaelin WG (2003) Chemosensitivity linked to p73 function. Cancer Cell 3: 403-410

20. Nicoletti I, Migliorati G, Paggliacci MC, Grignani F and Riccardi C (1991) A rapid and simple method for measuring thymocyte apoptosis by propidium iodide staining and flow cytometry. J. Immunol. Methods 139: 271-279

21. Eichhorst ST, Müller M, Li-Weber M, Schulze-Bergkamen $H$, Angel $P$ and Krammer PH (2000) A novel AP-1 element in the CD95 ligand promoter is required for induction of apoptosis in hepatocellular carcinoma cells upon treatment with anticancer drugs. Mol. Cell. Biol. 20: 7826-7837

22. Wu GS, Burns TF, McDonald ER, Jiang W, Meng R, Krantz ID, Kao G, Gan DD, Zhou JY, Muschel R, Hamilton SR, Spinner NB, Markowitz S, Wu G and ElDeiry WS (1997) KILLER/DR5 is a DNA damage-inducible p53-regulated death receptor gene [letter]. Nat. Genet. 17: 141-143

23. Liu X, Yue P, Khuri FR and Sun SY (2004) p53 upregulates death receptor 4 expression through an intronic p53 binding site. Cancer Res. 64: 5078-5083

24. Chau BN, Chen TT, Yisong Y, DeGregori J and Wang JYJ (2004) Tumor necrosis factor alpha-induced apoptosis requires p73 and c-ABL activation downstream of RB degradation. Mol. Cell. Biol. 24: 4438-4447

25. Micheau O, Solary E, Hammann A and Dimanche-Boitrel MT (1999) Fas ligand-independent, FADD-mediated activation of the Fas death pathway by anticancer drugs. J. Biol. Chem. 274: 7987-7992

26. Boldin MP, Mett IL, Varfolomeev EE, Chumakov I, Shemer-Avni Y, Camonis JH and Wallach D (1995) Self-association of the 'death domains' of the p55 tumor necrosis factor (TNF) receptor and Fas/APO1 prompts signaling for TNF and Fas/AP01 effects. J. Biol. Chem. 270: 387-391

27. Melino G, Bernassola F, Ranalli M, Yee K, Zong WX, Corazzari M, Knight RA, Green DR, Thompson C and Vousden KH (2003) p73 induces apoptosis via PUMA transactivation and Bax mitochondrial translocation. J. Biol. Chem. 279: 8076-8083

28. Terrasson J, Allart S, Martin H, Lule J, Haddada H, Caput D and Davrinche C (2005) p73-dependent apoptosis through death receptor: impairment by human cytomegalovirus infection. Cancer Res. 65: 2787-2794

29. Tannapfel A, Wasner M, Krause K, Geissler F, Katalinic A, Hauss J, Mossner J, Engeland $K$ and Wittekind $C$ (1999) Expression of p73 and its relation to histopathology and prognosis in hepatocellular carcinoma. J. Natl. Cancer Inst. 91: 1154-1158

30. Sayan AE, Paradisi A, Vojtesek B, Knight RA, Melino G and Candi E (2005) New antibodies recognizing p73: comparison with commercial antibodies. Biochem. Biophys. Res. Commun. 330: 186-193

31. He TC, Zhou S, da Costa LT, Yu J, Kinzler KW and Vogelstein B (1998) A simplified system for generating recombinant adenoviruses. Proc. Natl. Acad. Sci. USA 95: 2509-2514

32. Miyashita T and Reed JC (1995) Tumor suppressor p53 is a direct transcriptional activator of the human bax gene. Cell 80: 293-299

33. De Laurenzi V, Raschella G, Barcaroli D, Annicchiarico-Petruzzelli M, Ranalli M, Catani MV, Tanno B, Costanzo A, Levrero M and Melino G (2000) Induction of neuronal differentiation by $\mathrm{p} 73$ in a neuroblastoma cell line. J. Biol. Chem. 275: 15226-15231

34. Tusher VG, Tibshirani R and Chu G (2001) Significance analysis of microarrays applied to the ionizing radiation response. Proc. Natl. Acad. Sci. USA 98: 5116-5121 
35. Hamilton SR and Aaltonen LA (2000) WHO: Pathology and Genetics (Lyon: IARC Press)

36. Sobin LH and Wittekind CH (2002) UICC: TNM Classification of Malignant Tumours 6th edn (New York: Wiley-Liss)

37. Tannapfel A, Anhalt K, Hausermann P, Sommerer F, Benicke M, Uhlmann D, Witzigmann $\mathrm{H}$, Hauss $\mathrm{J}$ and Wittekind $\mathrm{CH}$ (2003) Identification of novel proteins associated with hepatocellular carcinomas using protein microarrays. J. Pathol. 201: 238-249

38. Wada N, Matsumura M, Ohba Y, Kobayashi N, Takizawa T and Nakanishi Y (1995) Transcription stimulation of the Fas-encoding gene by nuclear factor for interleukin-6 expression upon influenza virus infection. J. Biol. Chem. 270: 18007-18012

39. El-Deiry WS, Kern SE, Pietenpol JA, Kinzler KW and Vogelstein B (1992) Definition of a consensus binding site for p53. Nat. Genet. 1: 45-49

40. Brazma A, Hingamp P, Quackenbush J, Sherlock G, Spellman P, Stoeckert C, Aach J, Ansorge W, Ball CA, Causton HC, Gaasterland T, Glenisson P, Holstege FC, Kim IF, Markowitz V, Matese JC, Parkinson H, Robinson A, Sarkans U, Schulze-Kremer S, Stewart J, Taylor R, Vilo J and Vingron M (2001) Minimum information about a microarray experiment (MIAME)-toward standards for microarray data. Nat. Genet. 29: 365-371 